\title{
Three dimensional velocity structure and accurate earthquake location in Changning-Gongxian area of southeast Sichuan
}

\author{
Feng Long ${ }^{1 *}$, ZhiWei Zhang ${ }^{2,1}$, YuPing Qi' ${ }^{1}$ MingJian Liang ${ }^{1}$, Xiang Ruan ${ }^{1}$, WeiWei Wu' ${ }^{1}$, GuoMao Jiang ${ }^{3}$, and \\ LongQuan Zhou ${ }^{4}$ \\ 'Seismological Bureau of Sichuan Province, Chengdu 610041, China; \\ ${ }^{2}$ College of Geophysics, Chengdu University of Technology, Chengdu 610059, China; \\ 3Emergency Administration of Yibin City, Yibin Sichuan 644000, China; \\ ${ }^{4}$ China Earthquake Networks Center, Beijing 100045, China
}

\section{Key Points:}

- Widespread lateral inhomogeneity exists in the velocity structure of the Changning-Gongxian area, southeast Sichuan; the location of the velocity anomaly is largely consistent with known structures

- The seismogenic structures of small earthquake clusters are different in size and occurrence in different sections of this region; the clusters have occurred primarily in regions with high $\mathrm{P}$ - or S-wave velocities

- The seismogenic structures of the Xingwen M5.7 and Changning M6.0 earthquakes are associated with NW-SE trending strike-slip faults, respectively in the south wing and the axis of the Changning-Shuanghe anticline, while that of the Gongxian M5.3 earthquake is associated with $\mathrm{N}-\mathrm{S}$ trending thrust faults in the Jianwu syncline region

Citation: Long, F., Zhang, Z. W., Qi, Y. P., Liang, M. J., Ruan, X., Wu, W. W., Jiang, G. M., and Zhou, L. Q. (2020). Three dimensional velocity structure and accurate earthquake location in Changning-Gongxian area of southeast Sichuan. Earth Planet. Phys., 4(2), $163-177$. http://doi.org/10.26464/epp2020022

\begin{abstract}
In order to understand the crustal structure and tectonic background of the Changning-Gongxiang area, southeastern Sichuan Province, where a series of moderate-to-strong earthquakes occurred in recent years, we utilized the seismic phase data both from a local dense array and from the regional seismic networks; we used the tomoDD program to invert for the high-resolution three-dimensional velocity structure within the depth range of 0-10 km and for accurate hypocentral locations in this area. We analyzed the seismogenic structures for the events of Xingwen M5.7 in 2018 and Gongxian M5.3 and Changning M6.0 in 2019. The results show that: (1) widespread lateral inhomogeneity exists in the velocity structure of the study area, and the location of the velocity anomaly is largely consistent with known structures. In the range of distinguishable depth, the inhomogeneity decreases with increasing depth, and the velocity structure anomalies in some areas are continuous in depth; (2) earthquakes occurred in clusters, showing the characteristics of zonal folding trends in the NW-SE and NE-SW directions; the focal depth in the area is generally shallow in both the sedimentary cap and the crystalline basement. The seismogenic structures of small earthquake clusters are different in size and occurrence in different sections, and the clusters occurred mostly in regions with high P-or S-wave velocities; (3) synthesis of a variety of data suggests that the seismogenic structures of the Xingwen M5.7 and Changning M6.0 earthquakes are associated with slip faults that trend NW-SE in, respectively, the south wing and the axis of the Changning-Shuanghe anticline, while that of the Gongxian M5.3 earthquake is associated with thrust faults that trend N-S in the Jianwu syncline region. The dynamic sources of the three earthquakes are all from the SE pushing of the Qinghai-Tibet block on the Sichuan basin; (4) the risk of future strong earthquakes in this area must be reevaluated in light of the facts (a) that in recent years, moderate-to-strong earthquake swarms have occurred frequently in southeast Sichuan; (b) that the complex structural area exhibits the easy-to-trigger characteristic, and (c) that the small-scale faults in this area are characterized by the phenomenon of stress "lock and release".
\end{abstract}

Keywords: southeastern Sichuan; Sichuan Basin; three-dimensional velocity structure; earthquake precise location

\section{Introduction}

After the $M 8$ Wenchuan earthquake of 2008 , a number of medi-

Correspondence to: F. Long, icy1111@163.com

Received 13 AUG 2019; Accepted 06 NOV 2019.

Accepted article online 14 JAN 2020.

C 2020 by Earth and Planetary Physics. um-strong earthquakes above M4.5 took place in the Sichuan Basin and its periphery, which prior to that time had been relatively quiet seismically. Among these events are the Suining M5.0 earthquake on Jan. 31, 2010; the Santai-Zitong M4.7 earthquake swarm, and multiple earthquake swarms around the Zigong-Yibin area in southeast Sichuan that include the Xingwen M5.7 of Dec.16, 2018; the Gongxian M5.3 of Jan.3, 2019; and the Changn- 
ing M6.0 swarm which started from June 17, 2019. Following a large earthquake, the occurrence of medium-strong earthquakes in neighboring places is generally considered to be related to regional stress adjustment (Rybicki, 1973; Wang R et al., 1980, 1983; Parsons et al., 2008). In the Sichuan Basin, such medium-strong earthquakes often occur as swarms; this phenomenon is especially prominent around the Changning-Gongxian area in southeast Sichuan (Figure 1a). Studies of seismicity characteristics and seismogenic mechanisms in the study region have been carried out for many years and have made significant progress (Ruan $\mathrm{X}$ et al., 2008; Long F et al., 2010; Zhu H and He C, 2014; Gong Y et al., 2015; Wu P et al., 2017; Sun XL et al., 2017; Meng LY et al., 2019; Lei $X L$ et al., 2017, 2019). Most of these studies have tried to seek the cause of the region's earthquake swarms by statistical comparison and analyses of different phenomena. However, due to the sparse station distribution in the early days, knowledge of the region's earth structure and medium property is still insufficient, which has hampered further study of the seismogenic mechanism. Starting from May of 2017 a dense observation array was deployed in the Changning-Gongxian area of Yibing City in southeast Sichuan, which served as the pilot program of the Sichuan-Yunnan National Earthquake Monitoring and Prediction Experimental Field; the purpose is to obtain fine earth structure details and accurate earthquake locations based on abundant observation data, thus providing a fundamental reference for determining the seismogenic mechanism.

The southeast Sichuan region is located in the west margin of the Yangtze Block at the junction of the Sichuan Basin and the Chuannan-Qianbei orogens, and borders in its periphery on the Chuandong fold belt, the Qianbei orogeny, and the Chuanzhong ancient uplift. In geological history, this region underwent multiple tectonic reformations, including those caused by the Caledonian, Hercynian, Indosinian, Yanshanian, and Himalayan tectonic movements (Qin ZP et al., 2013; Wang SZ et al., 2013). The geologic structures in the region are very complicated, consisting primarily of NE-, NW-, and EW-trending large-scale folding structures accompanied by faults in the corresponding directions. The tectonic deformation is characterized by long and narrow anticlines, broad and gentle synclines, and nose-like or short dome structures; surface faults are mainly small-scale (Figure 1b), mostly of compressional or transpressional types. The major structures in the sedimentary cover include the Changning-Shuanghe large anticline in the NW-axial direction and the Jianwu syncline in the EW-axial direction; the former is an anticlinorium, consisting of the Tenglong anticline, the Baixiangyan-Shizitan anticline, the Shuanghechang anticline, and other fold structures; the axis of the fold on the east side is in the NW direction, while on the west side the fold structures were affected by the NE-trending Huayingshan tectonic belt and their axes turned into the NE direction. At the same time, the fold structures in this region are accompanied by faults of different sizes and trends; the Sinian-Cambrian slip layer controlled the structure deformation in the lower part of the cover, the faults stop in the Silurian system upward, and converge into the Sinian-Cambrian slip layer downward; in the upper part, the structures are controlled by the Triassic slip layer, which mainly plays a role of regulating the tectonic deformation (Cun SC et al., 1996; Huang HY, 2018). Geological surveys indicate that the faults on the surface that accompany these structures are of small scale and do not show the geologic and geomorphic evidence of Quaternary activity (Sixth Division of the First Survey Team of Sichuan Geology Bureau, 1973; Sichuan Geology Bureau, 1976).

\section{Data and Method}

Starting in May of 2017, the Sichuan-Yunnan National Earthquake Monitoring and Prediction Field deployed a temporary observation array around Changning-Gongxian of Yibing City in the south margin of the Sichuan Basin $\left(104.5^{\circ}-105.2^{\circ} \mathrm{E}, 28.0^{\circ}-28.6^{\circ} \mathrm{N}\right)$, consisting of 21 short period portable stations; the aperture of the array was about $10 \mathrm{~km}$ and the monitoring ability reached $M_{\mathrm{L}} 0.5$. In order to better constrain the events in the margin of the study region, this paper also used arrival time data from some stations of the regional networks of the Sichuan, Yunnan, and Guizhou Provinces; the total station number is 35. By September of 2018, this array had recorded a total of 5252 seismic events; the smallest event was $M_{\mathrm{L}} 0$ and the largest was $M_{\mathrm{L}} 4.7$ (Figure 2a); the observations totaled $39129 \mathrm{Pg}$ phase data and $37678 \mathrm{Sg}$ data. The monthly frequency plot shows that the number of earthquake records does not change severely, indicating that the continuity of the array operation has generally been good (Figure 2b); on the other hand, the record numbers show that some stations (about 12 stations) produced relatively fewer records, which we attribute mostly to large epicentral distances and unclear first arrivals, but a few stations may also have had operational problems; most stations' record numbers are above 1000 (Figure 2c). The linearity of the Wadati curve is generally good; the $\mathrm{P}$ wave travel times of most data are within 8 seconds, and the S-P time differences are within 6 seconds. In order to keep as much structural information as possible when discarding incorrect phase data, we selected data falling within 2.5 times the standard deviation from the fitting curve (Figure 3). At the same time, to ensure that the numbers of $\mathrm{P}$ and $\mathrm{S}$ data are identical we used only paired $\mathrm{P}$ and $\mathrm{S}$ data; there were altogether 39066 such pairs.

The accuracy of earthquake locations depends on an appropriate velocity model and selection of accurate travel time data. Available studies indicate that the velocity structure in the southeast Sichuan area is complex (Zhang ZW et al., 2013); accordingly, we chose the "multi-stage location" method (Long F et al., 2015) as best suited to determining accurate location results in this area. The procedure is as follows. First, the velocity structure of east Sichuan determined from inversion of natural and artificial seismic data (Zhao Z and Zhang RS, 1987) was used as the initial model for earthquake location and velocity structure inversion; in order to roughly assess each initial location result, HYPOINVERSE (Klein, 2002) was used to get the absolute locations in the study region; the result indicated that the average horizontal error was $1.072 \mathrm{~km}$, vertical error was $3.784 \mathrm{~km}$, and the travel time residual was $0.114 \mathrm{~s}$. We selected only events that were recorded by more than 8 stations, and carried out 200 iterations of bootstrap inversion of a minimum 1D velocity model (Kissling, 1988; Kissling et al., 1994, 1995), resulting in a new 1D velocity model of the region (solid black line in Figure 4). In this model, the velocity values above $15 \mathrm{~km}$ depth are generally smaller than the initial values (solid red line); an obvious low velocity layer at $6-8 \mathrm{~km}$ is prob- 

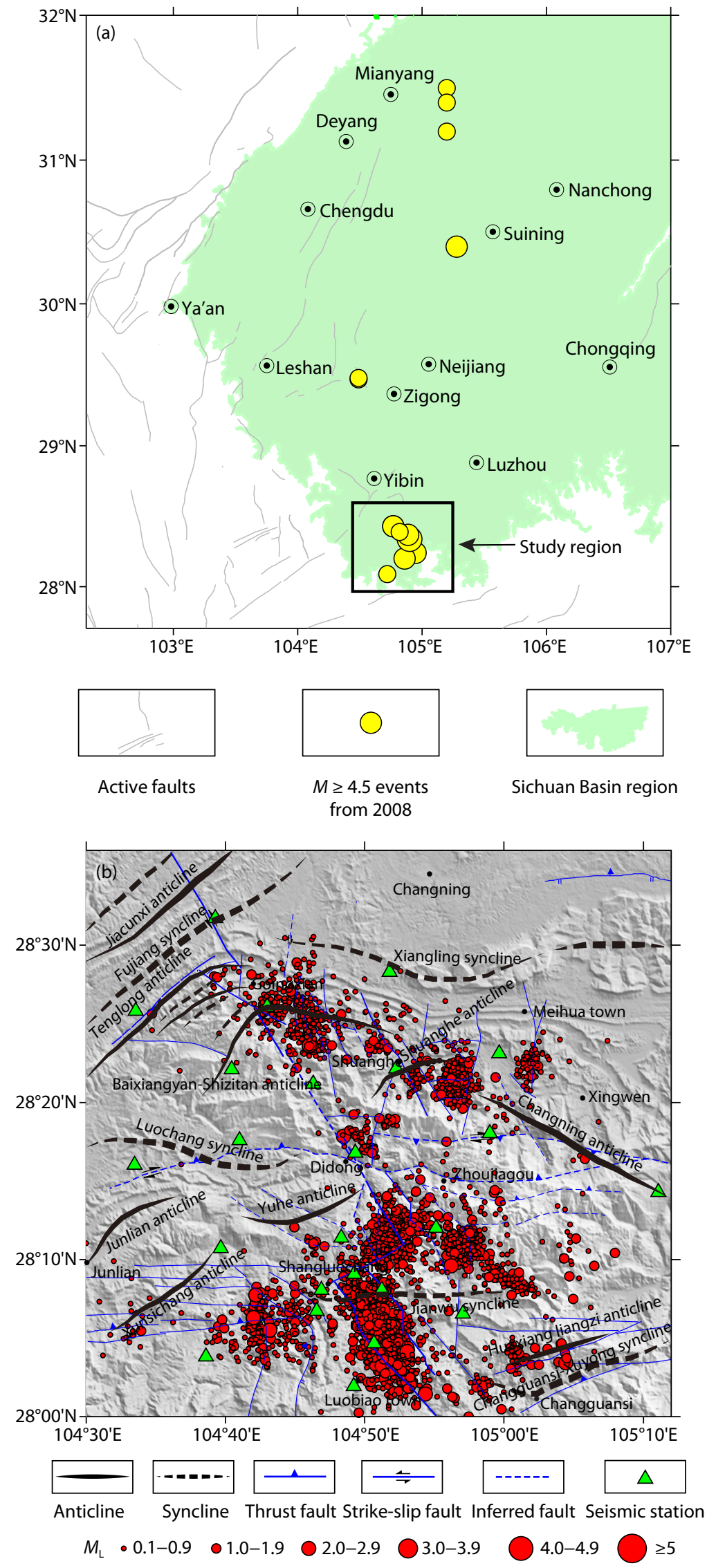

Figure 1. (a) Geological structures in Sichuan and surrounding areas and $M \geq 4.5$ earthquakes since 2008; (b) Geological structures, epicenters (2017.5-2018.9, $M_{\mathrm{L}} \geq 0.1$ ), and seismic stations in the study region. 

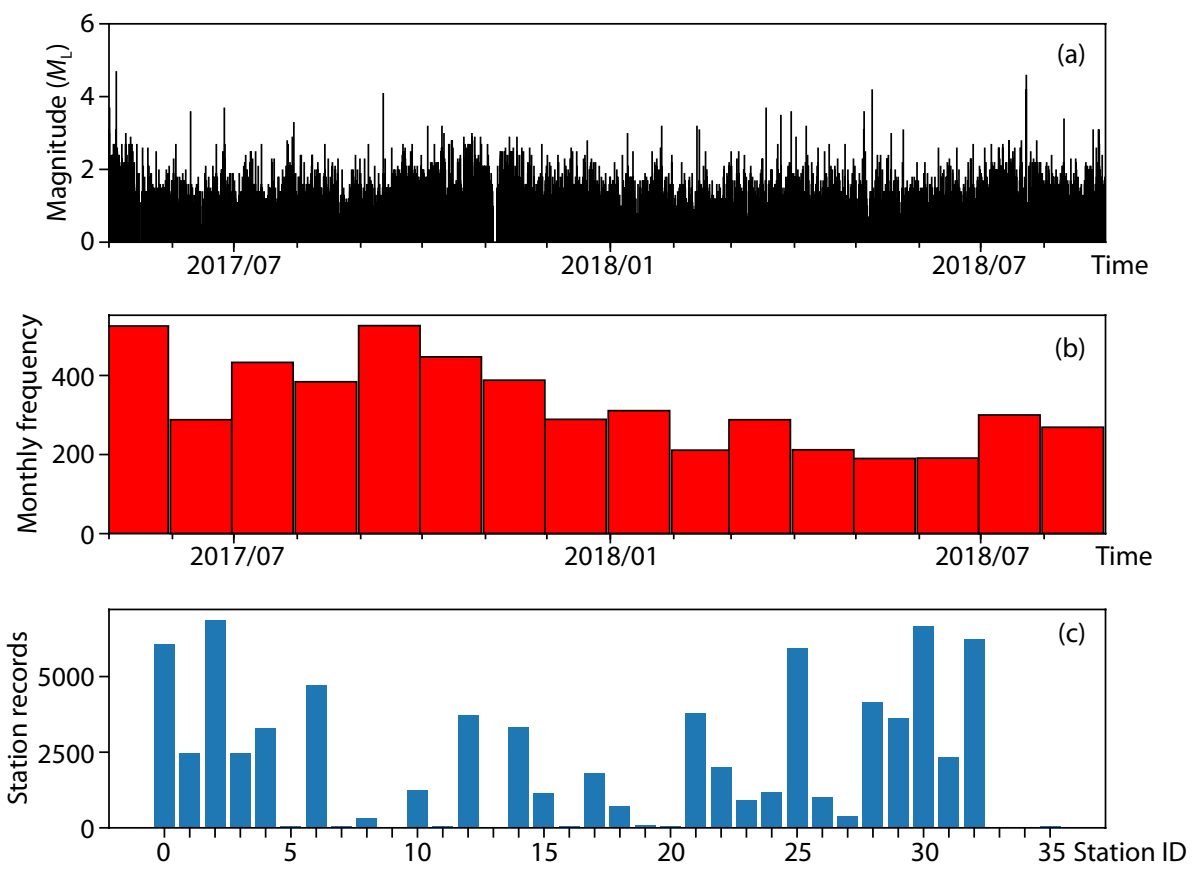

Figure 2. Diagrams of the $M-t(\mathrm{a}), N-t$ (b) and station record number histogram (c).

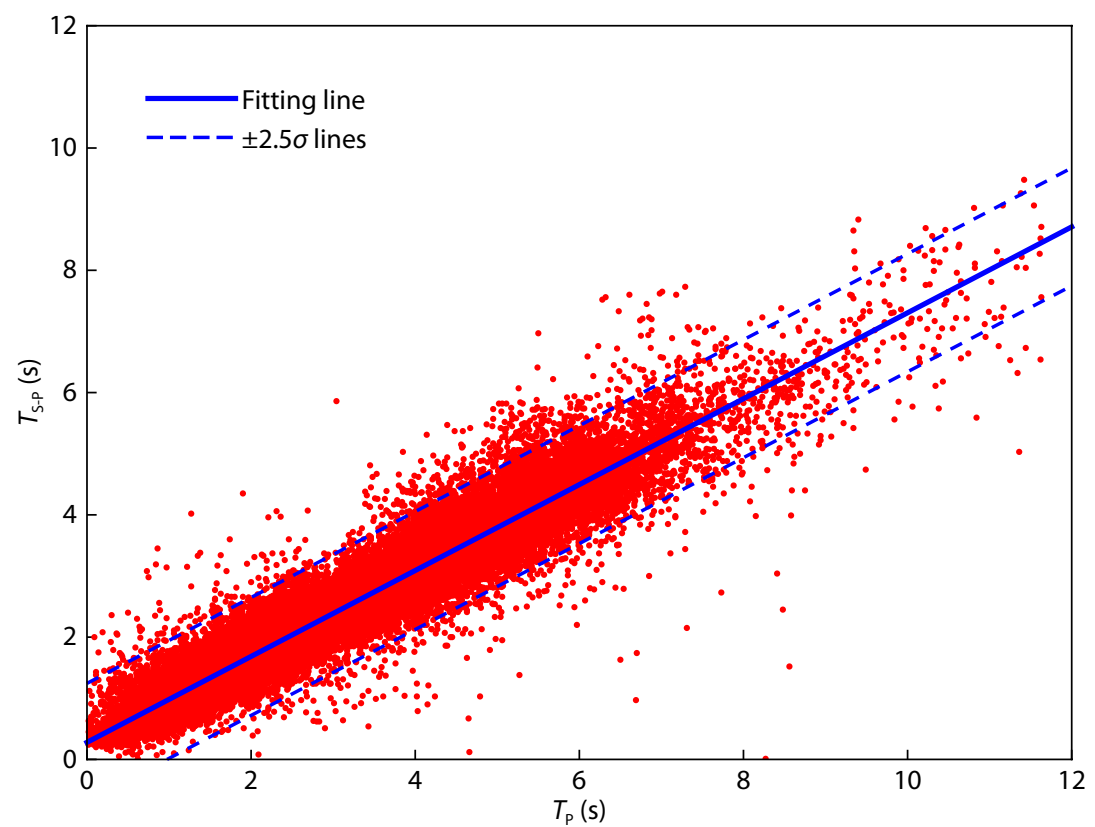

Figure 3. Wadati curve of the seismic array phase data.

ably related to the strong anisotropy in this region, but may also be due to the limited number samples; below $15 \mathrm{~km}$ the inverted and initial values made no difference, which may again be caused by data limitations. Utilizing the new velocity model with HYPOINVERSE to determine absolute locations, we found that the revised locations indicated average horizontal and vertical error of respectively 0.907 and $2.611 \mathrm{~km}$, with travel time residual of $0.093 \mathrm{~s}$, results that were significantly improved over the initial model, indicating that the new model suits the region better.

The tomoDD double difference tomography method (Zhang and Thurber, 2003, 2006) can simultaneously invert for the velocity structure and earthquake location using both the absolute and relative travel time data, resulting in high-accuracy 3D velocity structure and focal distribution; at present the method is widely used (Chiarabba and Amato, 2003; Okada et al., 2006, 2007; Hofstetter et al., 2012; Xiao Z and Gao Y, 2017; Wu HB et al., 2018; Wang $C Z, 2018$ ). We used the new velocity model and the location result as the initial values of velocity structure and focal position, and used the tomoDD method to calculate the velocity structure of the study region. The region is horizontally divided into $0.1^{\circ} \times 0.1^{\circ} \mathrm{grid}$; earthquake pairs for which the minimum record number was 8 were searched within a radius of $10 \mathrm{~km}$; the velo- 


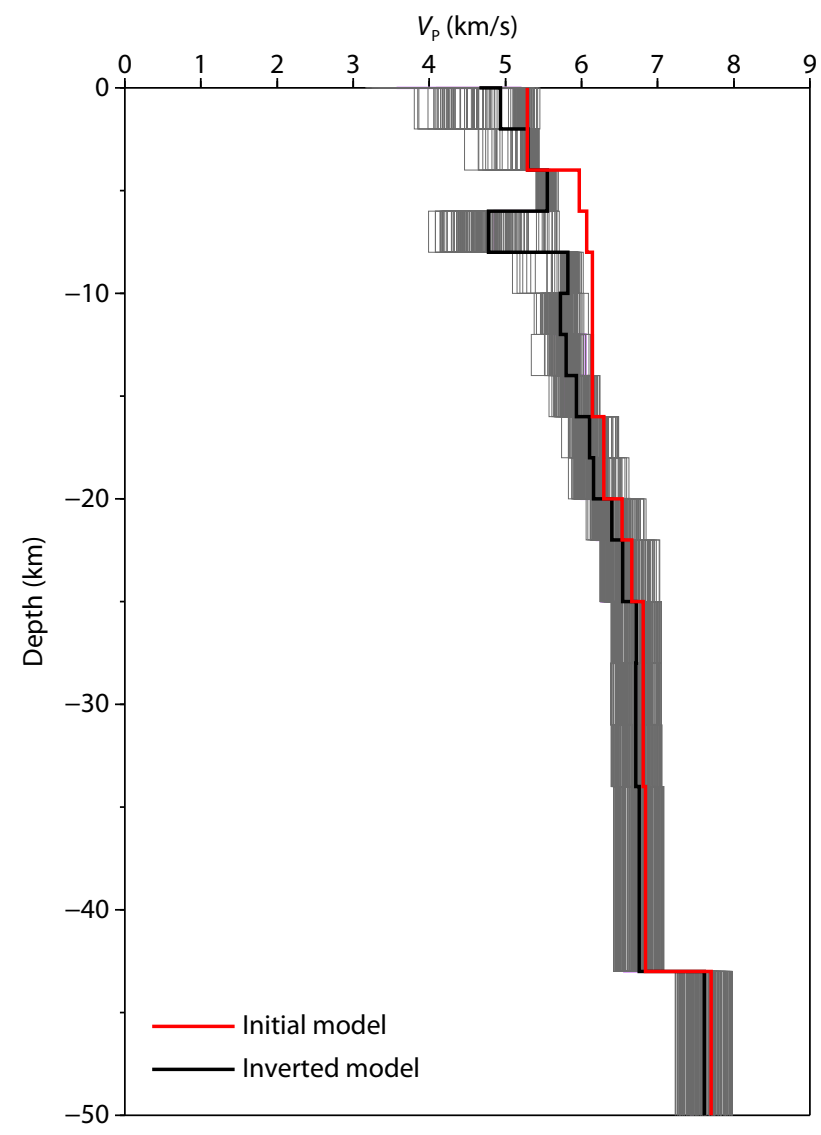

Figure 4. The minimum 1-D velocity structure model in the study region. Thick red line indicates the initial model, while thin gray lines indicate the single inversion results, thick black line shows the final mean value; few rays penetrate below $15 \mathrm{~km}$ in depth, using initial values from Zhao $Z$ et al., 1987.

city values at the depths of $0 \mathrm{~km}, 3 \mathrm{~km}, 5 \mathrm{~km}, 8 \mathrm{~km}, 10 \mathrm{~km}, 15 \mathrm{~km}$, $20 \mathrm{~km}$, and $25 \mathrm{~km}$ were obtained from inversion. In addition, the $\pm 5 \%$ pattern checkerboards were used to test the robustness and resolution of the inversion; the result indicated that at the surface $(z=0 \mathrm{~km})$ and the depths $3 \mathrm{~km}$ and $5 \mathrm{~km}$ most of the area can be correctly imaged except at the margin of the study region; however, as depth increases, the resolvable area diminishes - at the depth of $8 \mathrm{~km}$ only the core area can be resolved, and below $10 \mathrm{~km}$ the resolving power is lost entirely. Because the $\mathrm{P}$ and $\mathrm{S}$ wave data are paired, the checkerboard test result for $S$ wave is similar to that for P wave (Figure 5). The vertical checkerboard test along latitudinal and longitudinal directions shows that between $28.1^{\circ}-28.5^{\circ} \mathrm{N}$ and $104.6^{\circ}-105.1^{\circ} \mathrm{E}$ the resolution is generally acceptable (Figure 6). In the inversion, the elevation data of the dense array was used to eliminate the impact of relief on the travel times. Finally we re-located 4762 earthquakes; the horizontal and vertical relative error for the new locations was $0.43 \mathrm{~km}$ and $0.75 \mathrm{~km}$, respectively, the travel time residual was 0.04 seconds.

\section{Result and Analysis}

\subsection{Velocity Structure Anomaly}

We calculated $\mathrm{P}$ and $\mathrm{S}$ wave velocity disturbances at different depths; considering that the earthquakes are mainly distributed in two structural regions of the Changning-Shuanghe anticlinorium and the Jianwu syncline, we delineated the scope of the two structural regions according to the stratigraphic boundaries (Figure 7c). The velocity distributions at $0 \mathrm{~km}$ depth (Figure 7) show that there are conspicuous $P$ and $S$ wave low velocity anomalies in the southern part of the study region, with an amplitude between $-20 \%$ and $-10 \%$. The core area of the low velocity anomaly is located in the Jianwu syncline; its size is about $20 \mathrm{~km}$, and the overall trend is in the NNW or near-NS direction (the south part of the $\mathrm{P}$ anomaly deviates toward the west), which is consistent with the strike of several NNW-trending faults in the low velocity anomaly zone, possibly implying a certain relation between the two, but is not consistent with the near-EW trend of the Jianwu syncline. A high velocity anomaly exists on the east of the low velocity anomaly, with amplitude between $5 \%$ and $20 \%$ and size about 20-30 km, in the NNE or near-NS direction; it crosses the middle part of the Changning anticline and extends along the southern part of the anticline to the vicinity of the Jianwu syncline (Figure 7a); the dominant distribution direction of the high velocity anomaly is inconsistent with the trends of all vicinal structures of various size. Viewed together with the stratigraphic sequence (Figure 7c) and elevation (Figure 7d), we conclude that the low velocity anomaly is mainly distributed in the areas of Triassic-Jurassic systems and elevation 600-1000 m, while the high velocity anomaly is in the Ordovician-Triassic of elevation 800-1400 m (Sixth Division of the First Survey Team of Sichuan Geology Bureau, 1973; Sichuan Geology Bureau, 1976; Lei XL et al., 2017); in the northern part of the study region some low-amplitude P-wave low velocity anomalies show a trend of distribution along the periphery of the Triassic strata. In summary, the nearsurface velocity anomalies can be summarized as high velocity anomalies in old strata at high elevation and low velocity anomalies in new strata at low elevation.

At the depth of $3 \mathrm{~km}$, the $\mathrm{P}$ and $\mathrm{S}$ wave high velocity anomalies are distributed in the south wing of the Changning-Shuanghe anticline and around Shangluochang in the west section of the Jianwu syncline (Figure $8 a$ and b); the anomaly amplitude is greater than $5 \%$, and the size is between 20 and $30 \mathrm{~km}$. The low velocity anomalies are distributed in the east section of the Jianwu syncline (amplitude $-5 \%$ ) and in an area north of the axis of the Changning anticline (amplitude $-10 \%$ to $-5 \%$ ). The $S$ wave anomalies are distributed mainly in the east of the Baixiangyan-Shizitan anticline (amplitude $-10 \%$ to $-5 \%$ ) and in the east section of the Jianwu syncline (amplitude $-5 \%$ ). At this depth, earthquakes are relatively more abundant, distributed primarily in the high velocity zones or in the boundary area between high and low velocities (Figure $8 \mathrm{~b}$ ). The persistent low velocity anomaly in the Jianwu syncline from 0 to $3 \mathrm{~km}$ depth may be related to the relatively young rock stratum in the core; the earthquakes occur mostly in the older strata to its north and south.

At the depth of $5 \mathrm{~km}$, the $P$ wave high velocity anomalies are distributed mainly in the eastern part of the Baiziangyan-Shizitan anticline and in the Jianwu syncline (amplitude of 5\% -10\%); earthquakes are dense in these areas (Figure $8 \mathrm{c}$ ), and $\mathrm{S}$ wave high velocity anomalies are not obvious (Figure $8 \mathrm{~d}$ ). The $P$ wave low velocity anomalies are distributed in the middle part of the Changn- 



Figure 5. $\mathrm{P}$ and $\mathrm{S}$ wave checkerboard resolution at different depths.

ing anticline (amplitude about $-5 \%$ ), and the $S$ wave low velocity anomaly appearing at depth $3 \mathrm{~km}$ in the eastern part of Baixiangyan-Shizitan anticline persists here, but the amplitude is lower (about $-5 \%$ ). Most earthquakes occurred in the depth range of 3-5 km, which is basically consistent with that of the Sinian-Cambrian sedimentary strata from geophysical prospecting and drilling (Cun SC et al., 1996; Huang HY, 2018), indicating that the seismicity in the study region is controlled primarily by the structures in the sedimentary cover. Because the faults in the sedimentary cover are controlled mainly by the Sinian-Cambrian detachment layer below, and stop extending upward in the Silurian system, most of the faults in this area are blind faults, except a few lying close to the core of the anticline; this is also the primary reason that earthquake activity is concentrated in the $3-5 \mathrm{~km}$ depth range.

At the depth of $8 \mathrm{~km}$, the velocity is no longer resolvable in the larger part of the Changning-Shuanghe anticline (Figure $8 \mathrm{e}$ and $f)$; however, it seems that in the south wing of the Changning anticline, from the Shuanghe anticline southward to the Jianwu syncline, there are respectively $\mathrm{P}$ wave low velocity (Figure $8 \mathrm{e}$ ) and $\mathrm{S}$ wave low velocity anomalies (Figure $8 f$ ). Because earthquakes close to this depth are relatively fewer, determination of these anomalies is not very reliable. No fault of considerable size is known to exist in this area, and it is generally considered that the stratum at this depth should be the pre-Sinian basement (Guo ZW et al., 1997); the Sinian-Cambrian detachment layer near this depth may be an important stratum to coordinate the regional stress field and tectonic deformation, as well as the major factor controlling the seismicity in the region.

Inspecting the relatively reliable velocity anomalies in the depth range $0-5 \mathrm{~km}$, the horizontal inhomogeneity tends to decrease gradually from the surface $( \pm 20 \%)$ to the deep part $( \pm 5 \%)$, indicating that even in the sedimentary cover the medium is more homogeneous in the lower part than in the shallow layer.

\subsection{Spatial Distribution of Wave Velocity Ratio}

Theoretically, the accuracy of the $V_{S}$ model from arrival time inversion is lower than that of the $V_{P}$ model, due to the lower accuracy of $S$ wave phase picking. Therefore, the velocity ratio $V_{\mathrm{P}} / V_{\mathrm{S}}$ is generally not determined by division of the inverted $P$ and $S$ velocities; instead, it is acquired from a simultaneous inversion for $V_{P}$ and 

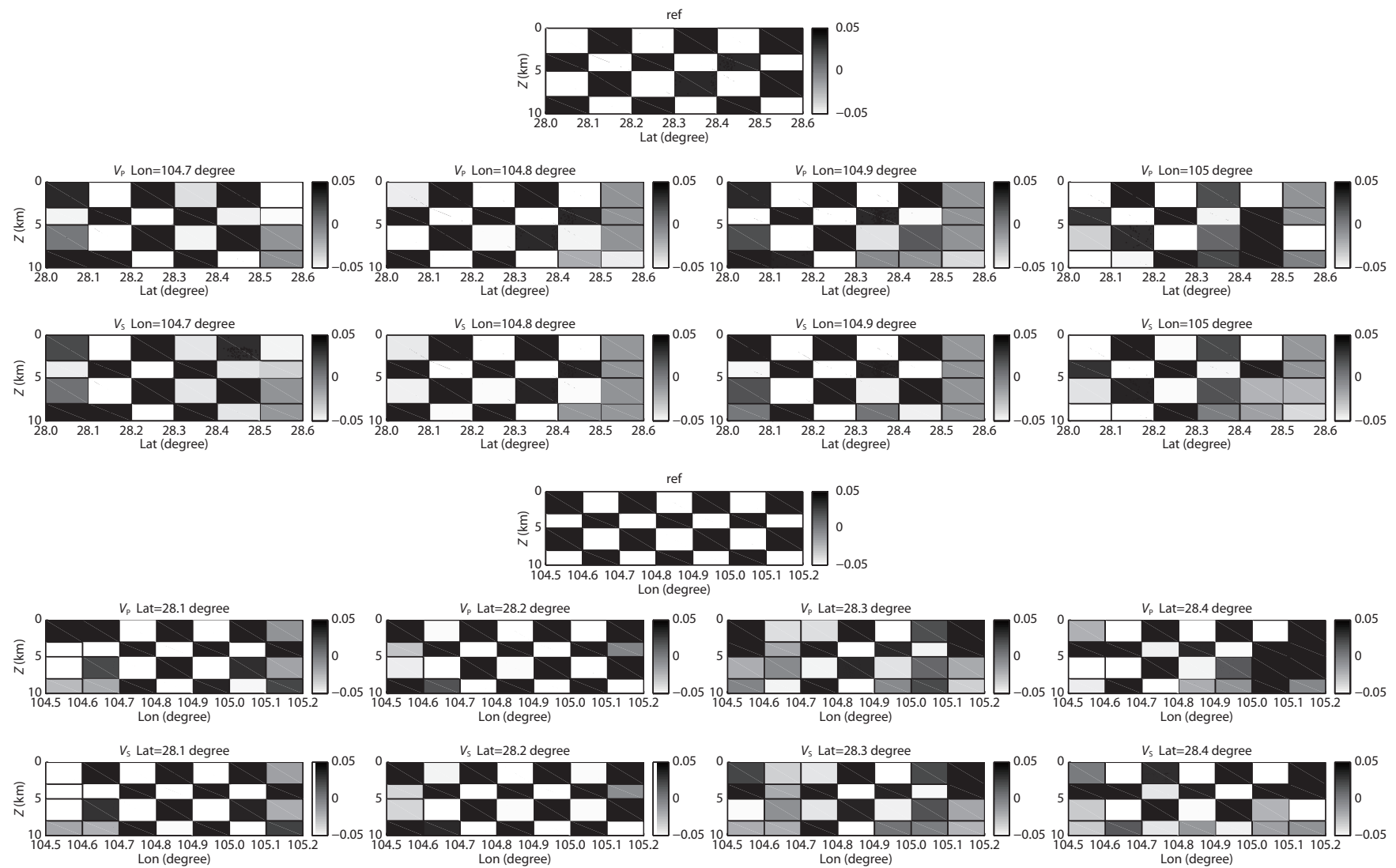

Figure 6. $\mathrm{P}$ and $\mathrm{S}$ wave checkerboard resolution along different longitudinal and latitudinal profiles.
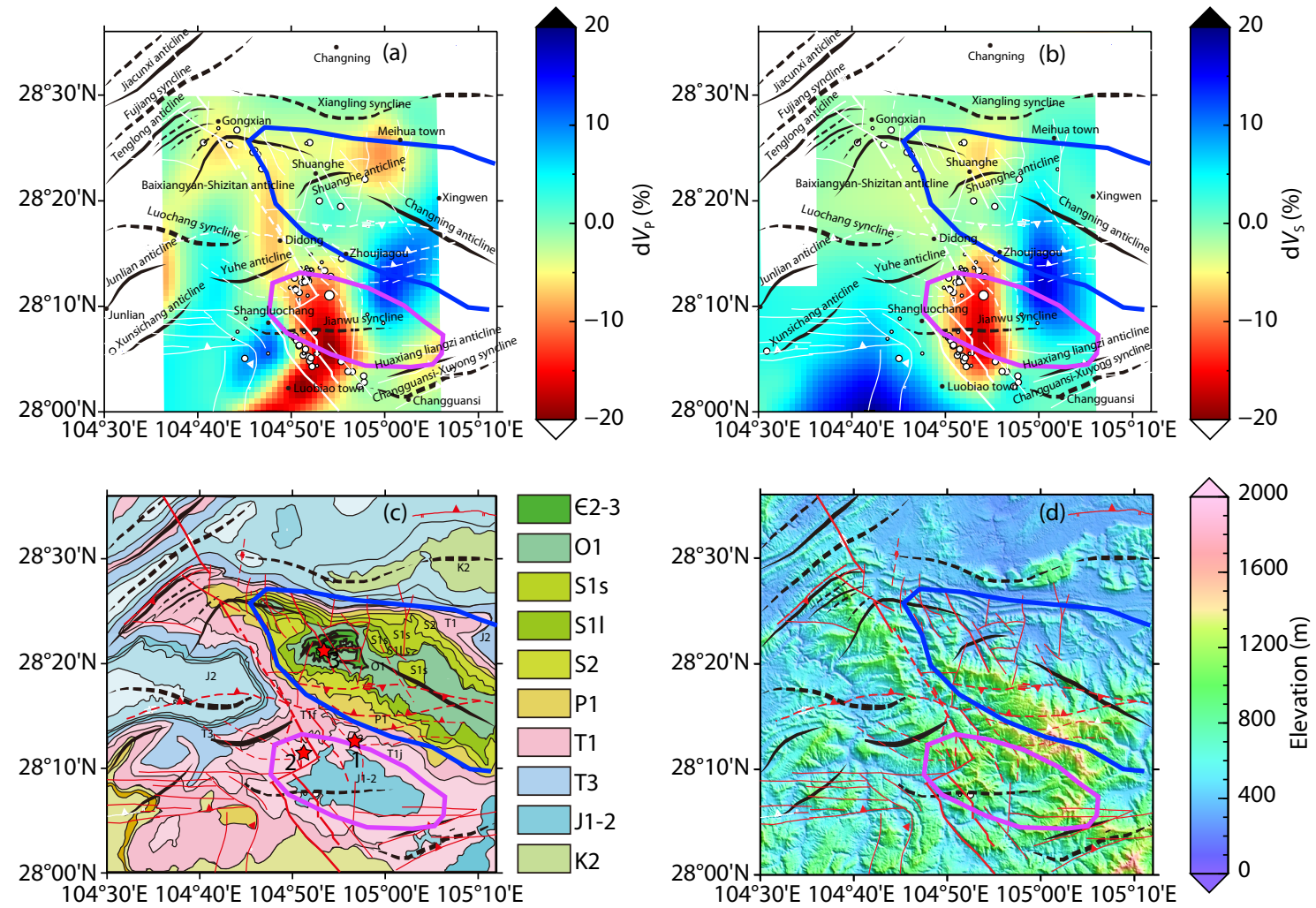

Figure 7. P wave velocity disturbance (a), S wave velocity disturbance (b), stratum (c) and elevation (d) at depth $0 \mathrm{~km}$. The blue line indicates the Changning-Shuanghe anticline region, the pink line indicates the Jianwu syncline region, and other symbols are interpreted as in Figure $1 \mathrm{~b}$. 

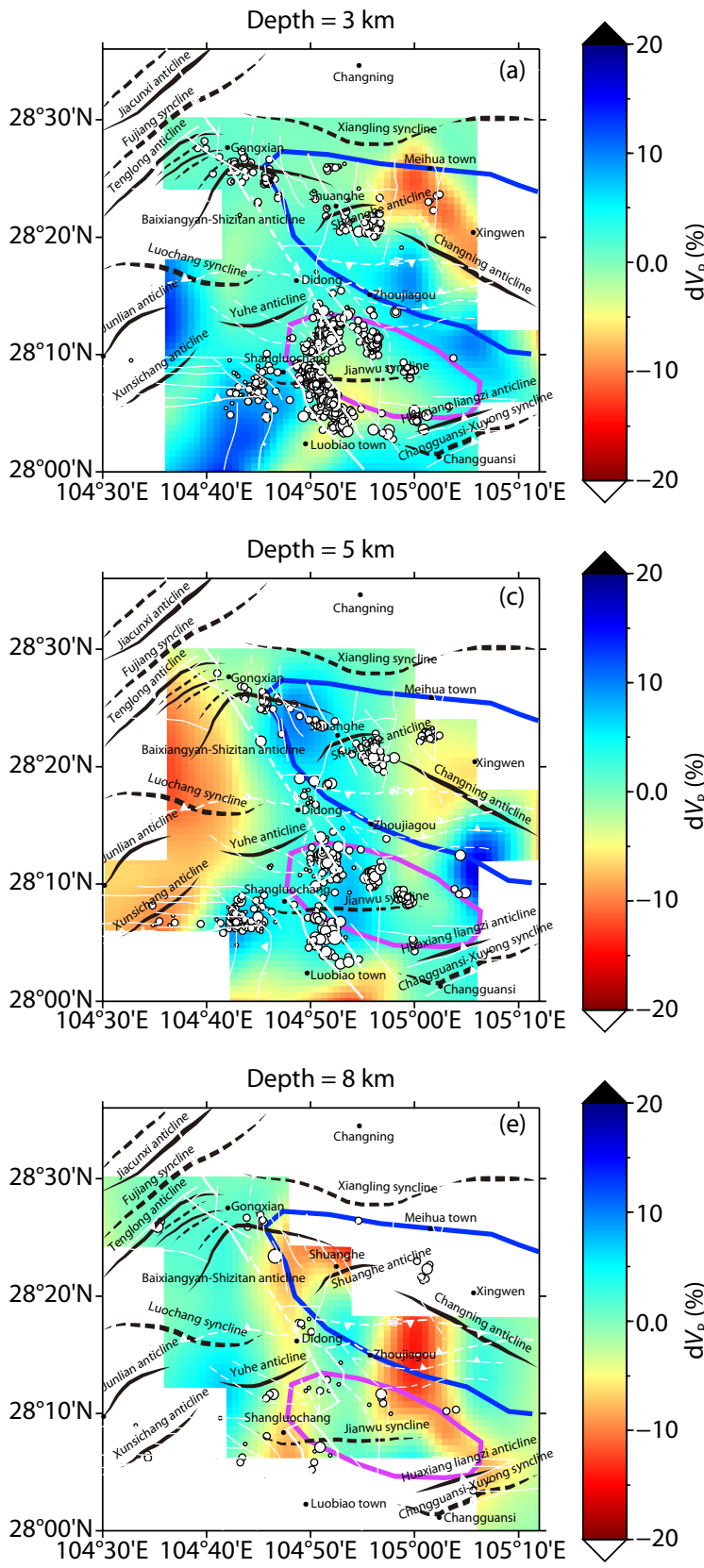
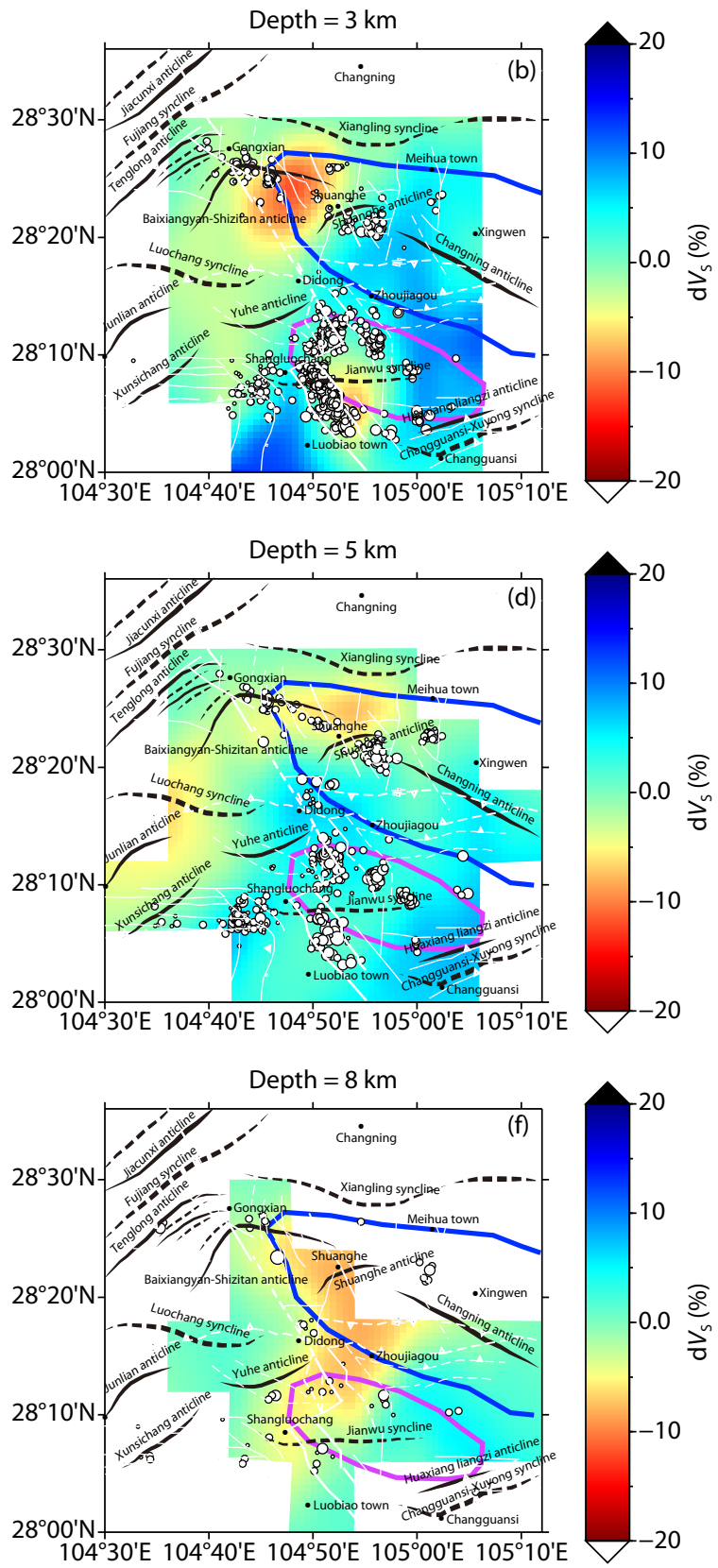

Figure 8. P wave velocity disturbance (left column), S wave velocity disturbance (right column) at different depths. Geological settings are the same as in Figure 1b; white circles indicate the earthquakes within the range in corresponding depth $\pm 0.5 \mathrm{~km}$; white lines indicate the faults.

$V_{\mathrm{P}} / V_{\mathrm{S}}$ (Thurber, 1993; Thurber and Eberhart-Phillips, 1999; Mousavi et al., 2015). Nevertheless, if the resolutions of $P$ and $S$ are almost the same and the scale of spatial inhomogeneity of the velocity structure is much greater than the wavelength, division of $V_{p}$ by $V_{s}$ can to some extent describe the true velocity ratio (Nakajima et al., 2001). In this paper, we adopted this method to obtain the spatial distribution of $V_{\mathrm{P}} / V_{\mathrm{S}}$, and we analyze its characteristics qualitatively.

At $0 \mathrm{~km}$ depth, an area of small-scale high ratio $\left(V_{\mathrm{p}} / V_{\mathrm{S}} \approx 1.8\right)$ exists near Shangluochang in the western section of the Jianwu syncline in the south part of the study area (Figure 9a), while at Meihua Town in the north wing of the Changning anticline there is a low ratio $\left(V_{\mathrm{P}} / V_{\mathrm{S}} \approx 1.6\right)$ area (Figure $\left.9 \mathrm{a}\right)$. At the $3 \mathrm{~km}$ depth, these two anomalies expand in both amplitude and space (Figure 9b). In addition, high ratio $\left(V_{\mathrm{P}} / V_{\mathrm{S}}>1.8\right)$ also appears at the west end of the Changning anticline and in the eastern section of the Baixiangyan-Shizitan anticline (Figure 9b), its amplitude and scope also increasing at depth $5 \mathrm{~km}$. This phenomenon indicates that the velocity structure may be continuous between the two depths. The high and low ratio areas at $8 \mathrm{~km}$ are distributed primarily in the south wing of the Changning anticline (Figure 9d), but we shall not discuss these in detail because of the low reliability of the data.

\subsection{The Relationship Between Earthquake Location and Velocity Structure}

It is seen from the re-located epicenter map (Figure10) that the 

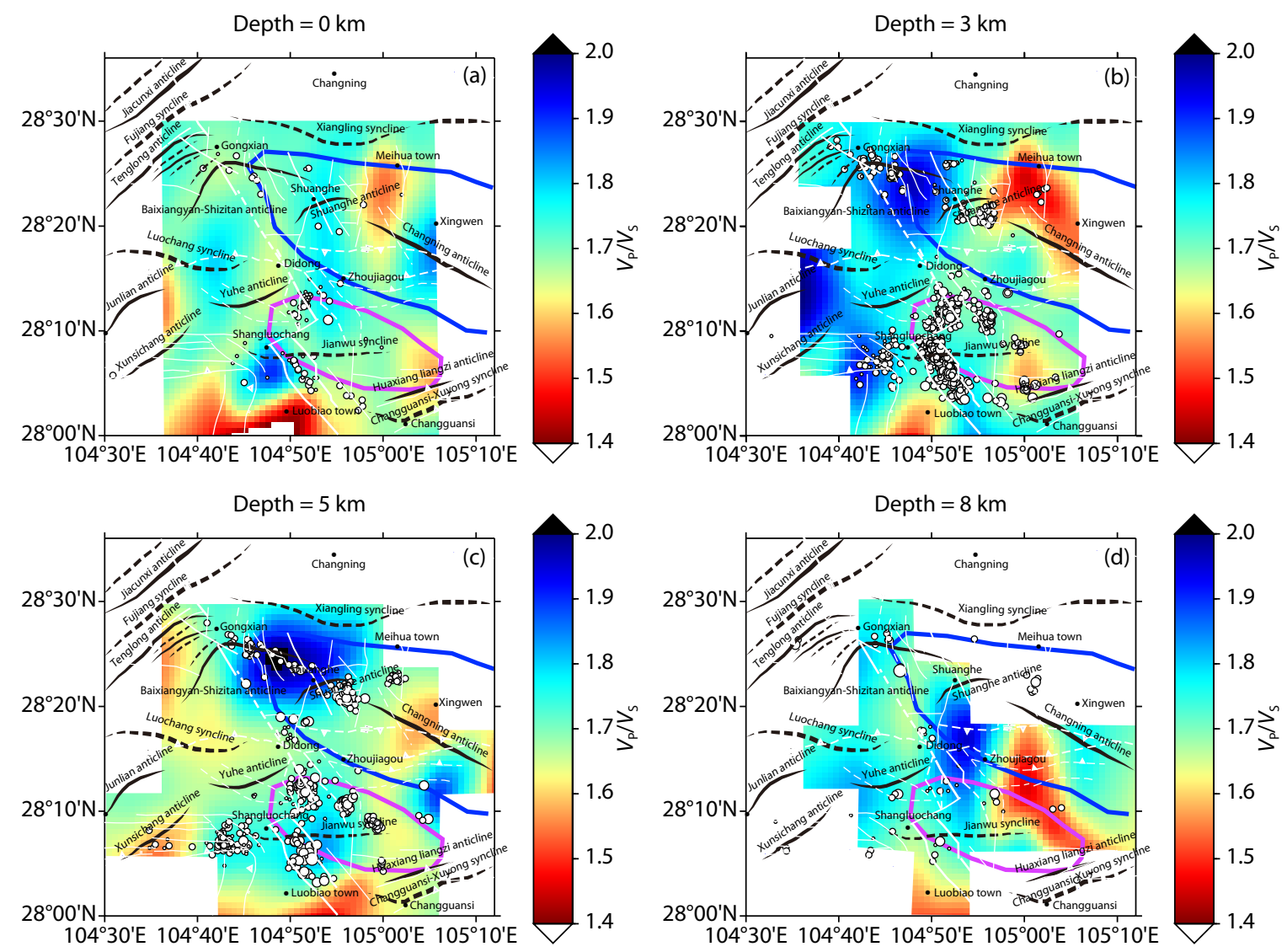

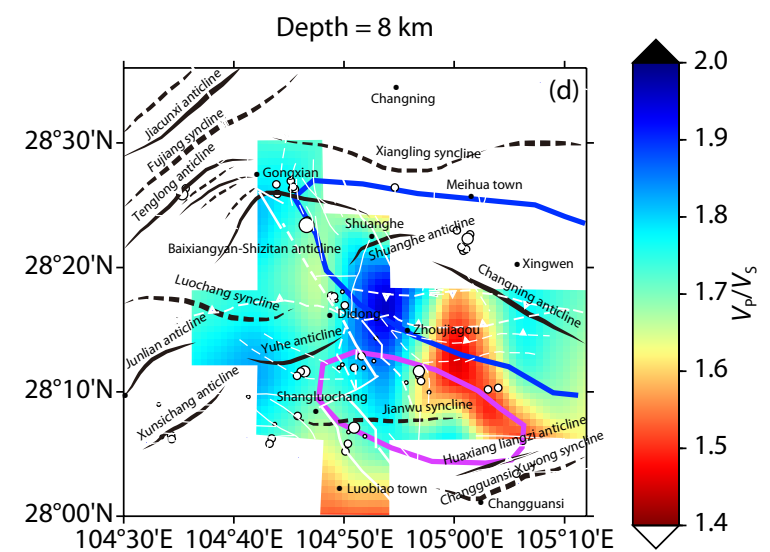

Figure 9. $V_{\mathrm{P}} / V_{\mathrm{S}}$ distribution map at different depths. Symbols are interpreted as in Figure 7.

earthquakes in the study region are obviously clustered, mainly in the Baixiangyan-Shizitan anticline, the west of the Shuanghe anticline, and the Changning anticline, and in an area bearing on the Jianwu syncline in the south; the configuration of this distribution displays a characteristic of alternatively folding of multiple NW-SE and NE-SW trending belts. The geologic structures in the region are of small scale and distributed in a complex way; no single cluster of earthquakes shows an obvious dominant direction, but the overall long axis of multiple adjacent clusters is generally consistent with the trend of the nearby geologic structure, e.g., the NWW-SEE trending distribution of small earthquakes along Gongxian-Shuanghe-Xingwen is highly consistent with the strike and location of the eastern section of the Baixiangyan-Shizitan anticline and the Changning anticline, and the NW-SE trending distribution of small earthquakes along Shangluochan-Luobiaozhen is very likely related to a set of parallel faults of the same strike in this area. In terms of the focal depth distribution, the great majority of earthquakes occurred above the depth of $6 \mathrm{~km}$, especially at 3 to $4 \mathrm{~km}$, indicating that the earthquakes in the study region are generally rather shallow. Considering that the average sediment thickness in the study region is $6 \mathrm{~km}$ (Wang WL et al., 2017) or 8 km (Xiong XS et al., 2015), most earthquakes should be caused by local ruptures of the sedimentary cover. In order to study the relationship between the occurrence of different earthquake clusters and the velocity distribution, we took 5 profiles in different areas (Figure 7) and collected the stratigraphic sequence data along some profiles (Wang SZ et al., 2013; Lei XL et al., 2017, 2019) to make a comprehensive analysis. It should be noted that the trend of any single cluster may not be consistent with the profile, but in a long profile the structural attitude can be manifested.

Profile $A A^{\prime}$ includes the east section of the Baixiangyan-Shizitan anticline and the Shuanghe anticline, and extends to the west side of the Changning anticline, with a length about $37 \mathrm{~km}$ (Figure 10); it is a longitudinal section of the Changning-Shuanghe anticlinal structure region. The profile (Figure 11a) shows that within $2 \mathrm{~km}$ below the surface there is a $P$ and $S$ wave low velocity layer containing mainly Cambrian-Triassic strata where relatively few earthquakes are observed. Owing to weathering and erosion, at the distance $17 \mathrm{~km}$ the Cambrian stratum is exposed on the surface; right at this location is a funnel-shaped S-wave low velocity zone that extends downward to the Cambrian basement. The earthquakes on the profile show obvious segmentation characteristics; the seismogenic structures and velocity structures of various earthquake clusters differ significantly. At $12 \mathrm{~km}$ of the profile the clustered earthquakes display a nearly upright and slightly NW-dipping fault which extends downward to $10 \mathrm{~km}$; considering the surface markers, this fault is probably the west section of the NE-SW trending Baixiangyan-Shizitan anticline, and is the near-surface boundary between the Triassic and Permian-Silurian systems of the west section of Changning anticline. The earthquake swarms at $20 \mathrm{~km}, 27 \mathrm{~km}$, and $30 \mathrm{~km}$ of the profile dip toward SE and do not reach to surface. Between 14 and $22 \mathrm{~km}$ of the profile and in the depth range 4 to $8 \mathrm{~km}$ there are some mediumsmall earthquake swarms of $M_{\mathrm{L}} 2-3$ which are obviously greater than the events nearby; this place is located in a high P-wave velo- 


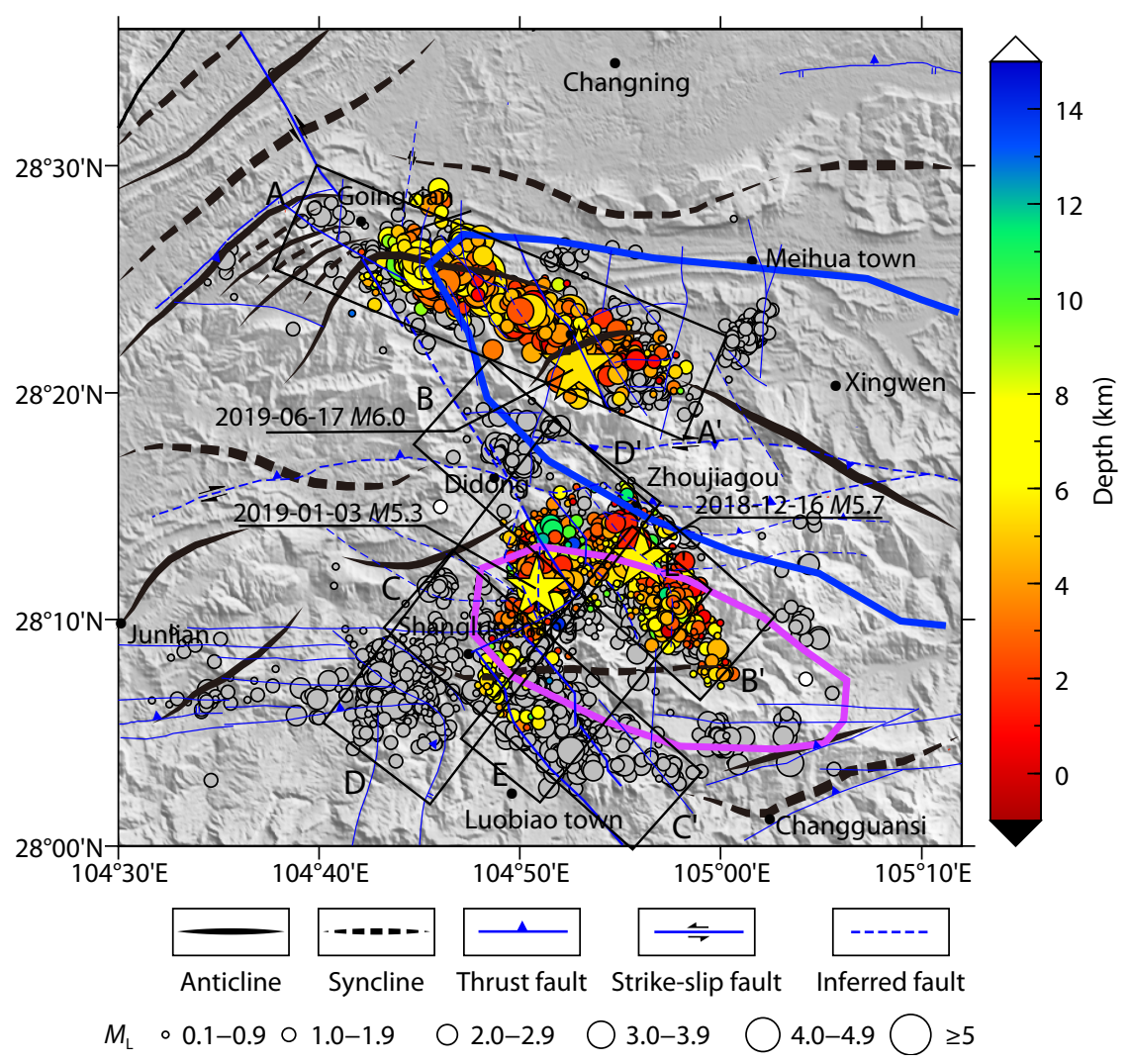

Figure 10. Map of relocated epicenters and profiles. Rectangles indicate the locations of profiles; uppercase letters show the positions of the start and end points of each profile; color circles indicate the epicenters from December 12, 2018 to July 31, 2019; stars illustrate the epicenters of $M>5$ events.

city zone (Figure 10a), and is also the lower boundary of a depressed S-wave low velocity zone (Figure 10b), and these small faults in the basement have not entered the sedimentary cover.

Profile $\mathrm{BB}^{\prime}$ contains a small NW-SE trending earthquake swarm; it is about $31 \mathrm{~km}$ long, located in the south wing of Changning anticline and entering into the Jianwu syncline. Similar to profile $A A^{\prime}$, the $P$ and $S$ wave velocities in the surficial $2 \mathrm{~km}$ are relatively low; however, at the distance $5 \mathrm{~km}$ from $\mathrm{B}^{\prime}$ the surficial velocity is remarkably higher than in other places of the profile at the same depth. The lateral inhomogeneity of the whole profile is conspicuous: e.g., at $10-20 \mathrm{~km}$ of the profile, there is a P-wave high velocity zone below $5 \mathrm{~km}$; traversing through the entire profile between depths $5-8 \mathrm{~km}$, there is an S-wave high velocity zone, indicating a very complex structure in this section. The earthquakes on the profile also show segmentation characteristics: the earthquakes on the NW side are relatively deep, their focal depths at 5 to $8 \mathrm{~km}$; the swarm at $15 \mathrm{~km}$ of the profile is relatively shallow, with a possibility of extending up to the surface, the fault dips slightly to SE and ends at a depth of $5 \mathrm{~km}$; further to the SE side the two swarms at 3-7 km are independent, but below $7 \mathrm{~km}$ they seem to be related in depth (Figure 11c). In this profile all earthquake swarms take place in the high S-wave velocity area (Figure 11d).

Profile CC' shows a NW-SE trending small earthquake swarm from Shangluochan to Luobiaozhen with a length of about $25 \mathrm{~km}$, is the southern boundary of Jianwu syncline (Figure 10). Both the $P$ and $\mathrm{S}$ wave velocities in the entire profile are characterized by relatively good lateral homogeneity. Earthquakes in this section are abundant and dispersed on the profile; medium-small earthquakes of $M_{\mathrm{L}}$ 2-3 are distributed below the clustered swarm area. At the NW end of the profile near the Yuhe anticline, there is a small cluster of earthquakes deeper than $5 \mathrm{~km}$; the fault plane is upright, slightly dipping to the SE (Figure 11e and f).

Profile DD' starts from the earthquake swarm in the south of Shangluochang, and crosses profiles $\mathrm{CC}^{\prime}$ and $\mathrm{BB}^{\prime}$ along the NE direction; it is a transverse section of the Jianwu syncline (Figure 10). The velocities in the profile are relatively homogenous laterally; the area of relatively low near-surface velocity at $15-30 \mathrm{~km}$ of the profile corresponds to the Jurassic stratum in the Jianwu syncline; furthermore, a relatively high $\mathrm{S}$ wave velocity zone exists around the $5 \mathrm{~km}$ depth, which corresponds to the Cambrian-Sinian strata and reveals the position of the top of the crystalline basement. In terms of the focal depth distribution, near the SW end of the profile $(0$ to $10 \mathrm{~km}$ ) in the vicinity of Shangluochang, the earthquakes in the depth tend to expand towards the SW; between this swarm and the swarm in the $\mathrm{CC}^{\prime}$ profile, there is a $5 \mathrm{~km}$ long section where small earthquakes are sparse (at 10 to $15 \mathrm{~km}$ along profile). To the southeast along the profile crossing $\mathrm{CC}^{\prime}$ and $\mathrm{BB}^{\prime}$, we can see three independent seismic clusters, whose lower boundary deepens successively. Therefore, along the $D \rightarrow D^{\prime}$ direction in the focal depth profile the lower boundary of the dense earthquake area changes generally from deep to shallow in the SW section and from shallow to deep in the NE section, displaying an upward 

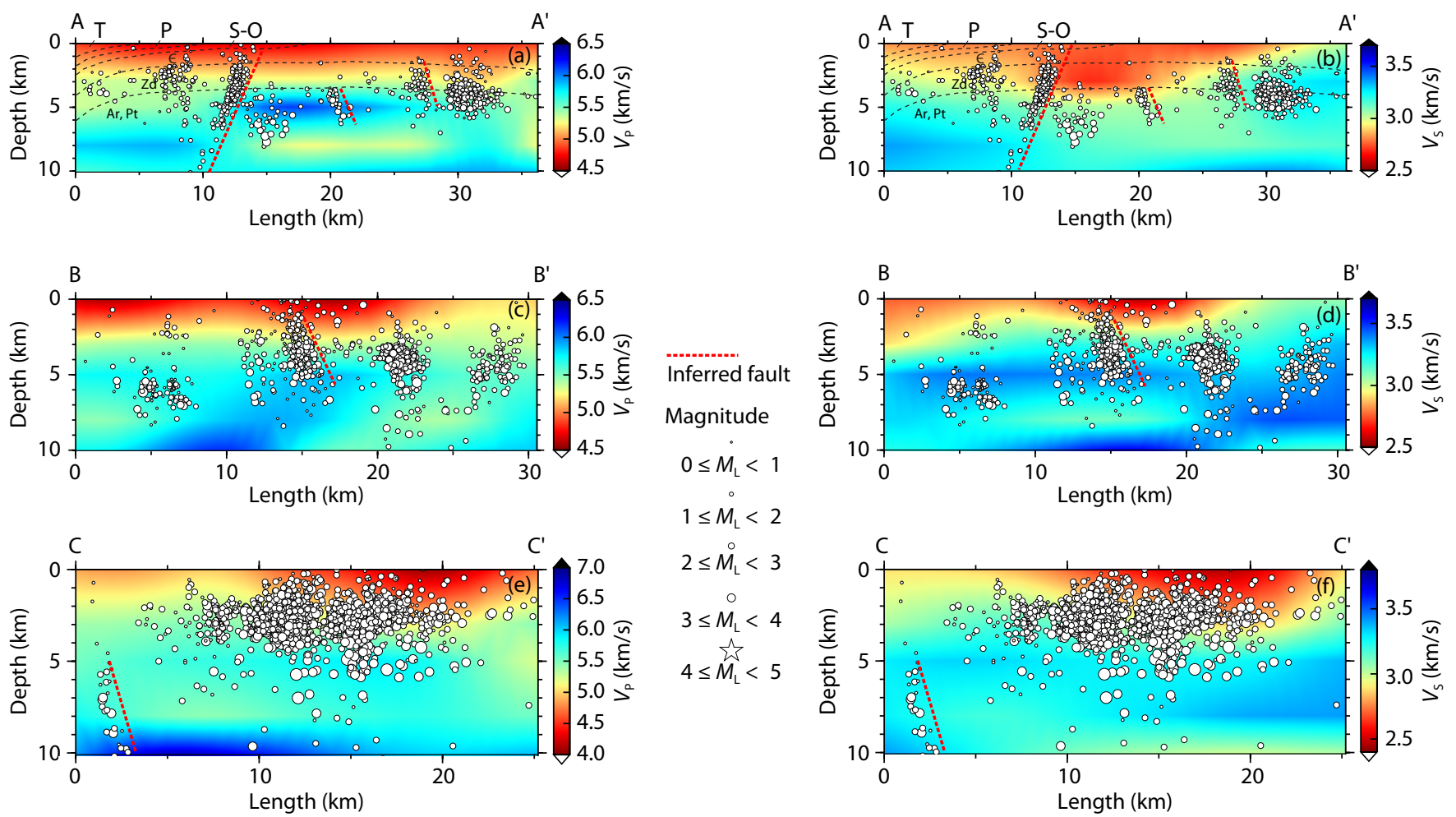

$2 \leq \dot{M}_{\mathrm{L}}<3$
$3 \leq \stackrel{\circ}{M_{\mathrm{L}}}<4$
$4 \leq \stackrel{\sum}{M}_{\mathrm{M}}<5$
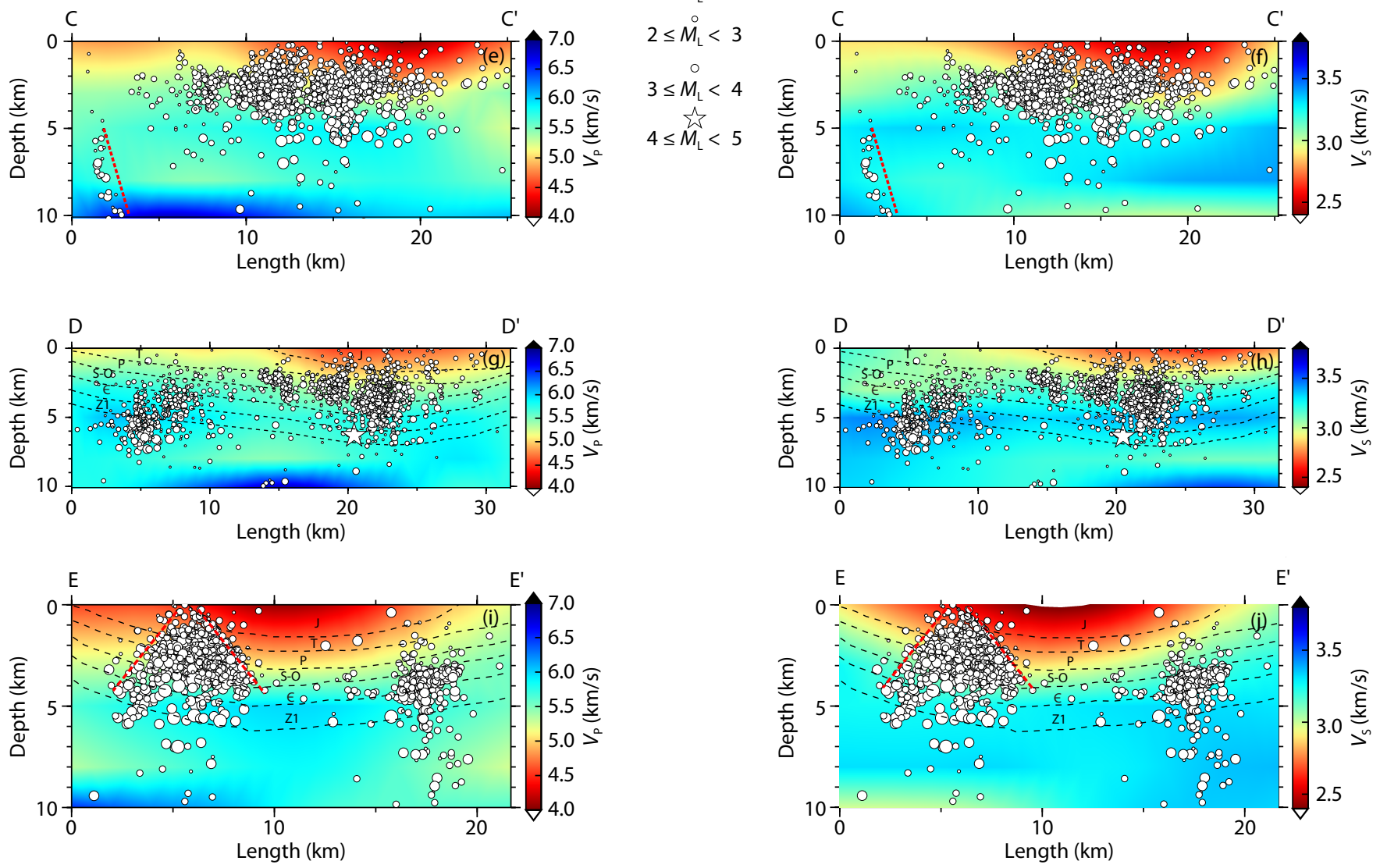

Figure 11. Different vertical cross-sections of $\mathrm{P}$ wave, $\mathrm{S}$ wave velocity structure and focal depth, and the probable seismogenic interpretation

protruding configuration. On May 4, 2017, at $13 \mathrm{~h} 40 \mathrm{~m}$ the Gongxian $M \mathrm{~L} 4.7$ earthquake (M5.5 according to the Sichuan network) occurred at the bottom of the earthquake cluster located at $20 \mathrm{~km}$ of the profile (Figure $11 \mathrm{~g}$ and $\mathrm{h}$ ). The faults in the profile are of small size, so the seismogenic structure of each earthquake cluster cannot be discerned.

Profile EE' starts from Luobiaozhen and crosses the middle section of profiles $\mathrm{CC}^{\prime}$ and $\mathrm{BB}^{\prime}$; the length of $\mathrm{EE}^{\prime}$ is about $22 \mathrm{~km}$ (Figure 10 ), and its velocity structure is partially similar to $\mathrm{DD}^{\prime}$. The transverse section of $\mathrm{CC}^{\prime}$ and $\mathrm{BB}^{\prime}$ on this profile is manifested as two earthquake clusters, The cluster at profile length 2 to $8 \mathrm{~km}$ is relatively shallower, mostly between depths 0 to $5 \mathrm{~km}$; the upper envelope of this cluster's dense zone displays an upward doming structure, narrow in its upper and broad in its lower parts; geological investigation (Sixth Division of the First Survey Team of Sichuan Geology Bureau, 1973) indicated that in this place there are two oppositely dipping faults. The other cluster, at 15 to $20 \mathrm{~km}$ of the profile, is concentrated between 3 and $5 \mathrm{~km}$ and is without particular or obvious distribution characteristic (Figure 11i and j).

\subsection{Relationship Between Velocity Structure and the Significant Earthquakes After Array Observation}

The above analysis is based on array observation data up to September of 2018; between then and July of 2019, a series of earthquakes occurred in the study region, including the Xingwen M5.7 earthquake on Dec. 16, 2018, the Gongxian M5.3 earthquake 
on Jan. 3, and the Changning M6.0 earthquake on June 17, 2019. Among them the Changning M6.0 earthquake is the largest earthquake in the basin ever since the beginning of recording. Because the array data after September, 2018, have not been processed, and the later earthquake location analysis has used different stations from the array, we have used observation data only from the Sichuan seismic station networks to carry out double difference relocation (Waldhauser and Ellsworth, 2000) for the above mentioned earthquake sequences. The relocated earthquake epicenters show that the Changning M6.0 earthquake sequence of June 17,2019 , is located in profile $A A^{\prime}$ of Figure 10, the Xingwen M5.7 sequence of Dec.16, 2018, is in profile BB', and the Gongxian M5.3 earthquake of Jan. 3, 2019, is in profile DD'; this indicates that these three earthquake sequences are still in the scope of previous seismicity (Figure 10).

Considering that all three of these large earthquakes took place at a depth of about $6 \mathrm{~km}$, we select the tomographic image of $5 \mathrm{~km}$ for analyzing the relation between velocity structure and earthquake location. The result indicates that basically all three earthquake sequences occurred in P-wave high velocity anomaly regions or at their boundaries (Figure 12). Among them, the Xingwen M5.7 and Gongxian M5.3 earthquake sequences in the south are located in weak high velocity anomalies within $5 \%$, whereas the Changning M6.0 earthquake sequence in the north is in an area where the $\mathrm{P}$-wave high velocity anomaly reaches above $10 \%$ (Figure 12a). On the other hand, the S-wave velocity anomalies give a contradictory result (Figure 12b): the two sequences in the south are located in weak S-wave high velocity anomaly regions (within 5\%), while the sequence in the north is in a remarkable low S-wave velocity anomaly zone $(-10 \%$ to $-5 \%)$. In terms of the wave speed ratio (Figure 12c), the two sequences in the south are located in a Poisson medium area with $V_{\mathrm{P}} / V_{\mathrm{S}} \approx 1.7$, while in the area of the Changning earthquake sequence in the north the wave speed ratio is as high as 2.0.

The replotted velocity structure and focal depth profiles for the three sequences indicate that profile $A A^{\prime}$, where the Changning M6.0 earthquake occurred, is divided at $15 \mathrm{~km}$ into two obviously different sections: on the east section, earthquakes are sparse and their focal depths are concentrated in the range of 0 to $6 \mathrm{~km}$, while on the west section the earthquakes are densely distributed in the depth range of 0 to $10 \mathrm{~km}$; the dense cluster reflects a fault dipping to the NW (Figure 13a and b), which should be the same structure with the NW-dipping fault in Figure $11(\mathrm{a}, \mathrm{b})$ at $12 \mathrm{~km}$ from end $A$ of the profile. Between 15 and $18 \mathrm{~km}$ from end $A$ there is a gap of small earthquakes within depth $4 \mathrm{~km}$, which is consistent with Figure $11(a, b)$; in this place, the S-wave low velocity zone is depressed, probably being a weak and soft region unfavorable to stress accumulation. However, between 4 and $8 \mathrm{~km}$ this section is a P-wave high velocity zone; most $M_{\mathrm{L}} \geq 3.0$ earthquakes took place here or in the vicinity. Relatively greater earthquakes occurred mostly in the crystine basement; small earthquakes extend upward into the sedimentary layer.

The Xingwen M5.7 earthquake took place in profile $\mathrm{BB}^{\prime}$, which also can be divided into an east and a west section by the mainshock; the earthquakes are relatively dispersive on the west side and dense in the west; this dense area just filled up the gap between two small earthquake clusters observed by the array data from May 2017 to September 2018 (pink circles in Figure 13c and d), indicating that slip locking and rapid stress releasing ("gap-filling" phenomenon) may also occur on small-scale fault segments, which are not the boundary between blocks and have no strong earthquakes. In the west section, the S-wave velocity is relatively high; the mainshock took place right on the margin of a P-wave and S-wave high velocity zone.

The Gongxian M5.3 earthquake occurred on profile DD' where the earthquakes are dispersive and the attitude of the seismogenic fault cannot be discerned; the mainshock is at the lower boundary of the aftershock zone. In the near-surface P-wave and S-wave low velocity zone, earthquakes are fewer, but in the high S-wave velocity area there seem to be small earthquake clusters (Figure $13 e, f)$.

In terms of geological structures, the Xingwen M5.7 earthquake epicenter is located near the junction of the south wing of the Changning-Shuanghe anticline and the Jianwu syncline, where there are no obvious active structures in the epicentral region; however, from geologic surveys it is conjectured that there are two sets of faults respectively in the NW-SE and E-W directions; among them, the NW-SE trending faults are parallel to the axis of the anticline axis, which should be caused by the low-rate southeasterly differential movement of the anticline and surrounding structures under the southeasterly tectonic stress from the Qing-

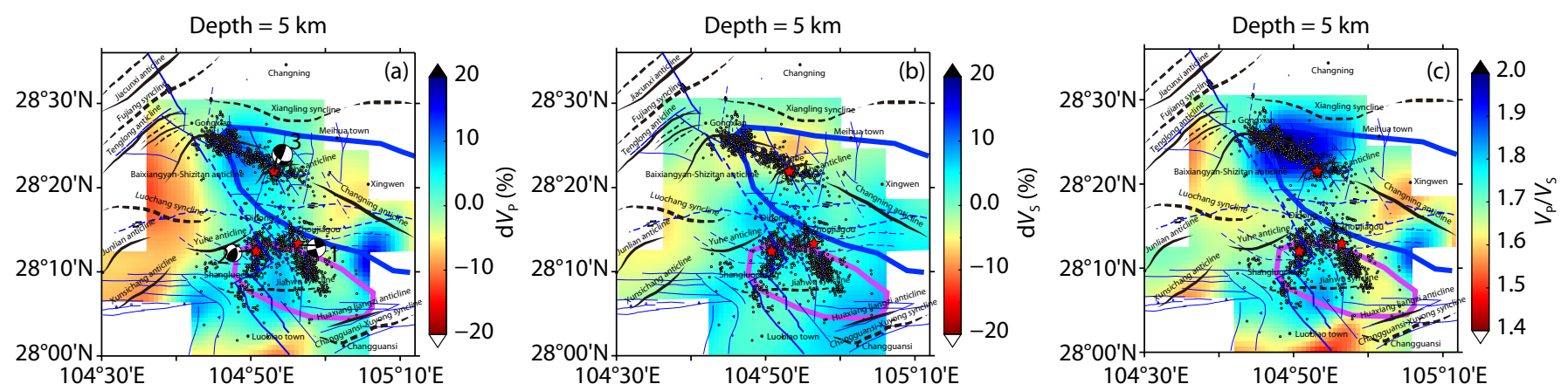

Figure 12. $\mathrm{P}$ wave velocity disturbance (a), $\mathrm{S}$ wave velocity disturbance (b) and $V_{\mathrm{P}} / V_{\mathrm{S}}$ (c) at $5 \mathrm{~km}$ depth. Geological settings are the same as Figure $1 \mathrm{~b}$; white circles indicate the epicenters of the 3 earthquake sequences from December 2018; stars shows the $3 M>5$ epicenters, and the numbers 1 to 3 in Figure 11 a represent the Xingwen M5.7, Gongxian M5.3, and Changning M6.0 earthquakes, respectively. 

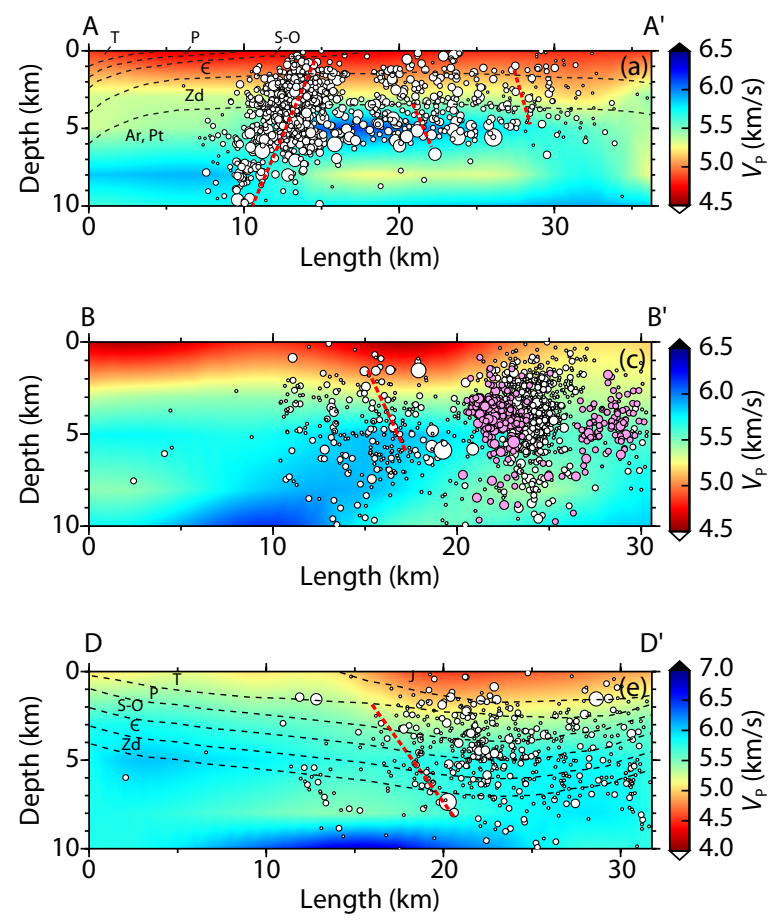

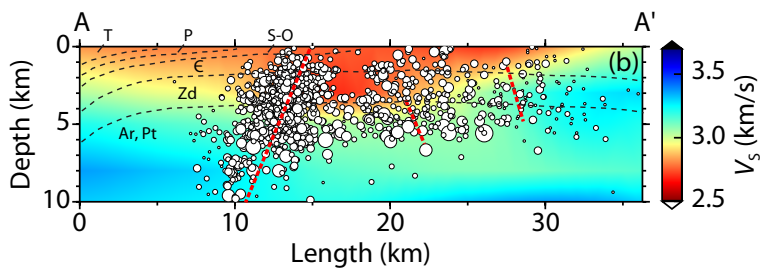

Magnitude

$0.1 \leq \dot{M}_{\mathrm{L}}<1$

$1 \leq \stackrel{\circ}{\mathrm{L}}<2$

$2 \leq \stackrel{\circ}{\mathrm{L}}<3$

$3 \leq \stackrel{\circ}{M}_{\mathrm{L}}<4$

$4 \leq \stackrel{\bigcirc}{M}_{\mathrm{L}}<5$

$5 \leq M_{\llcorner}<6$

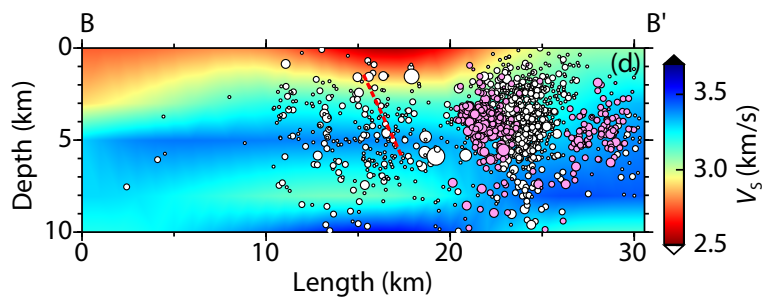

$M \geq 6$

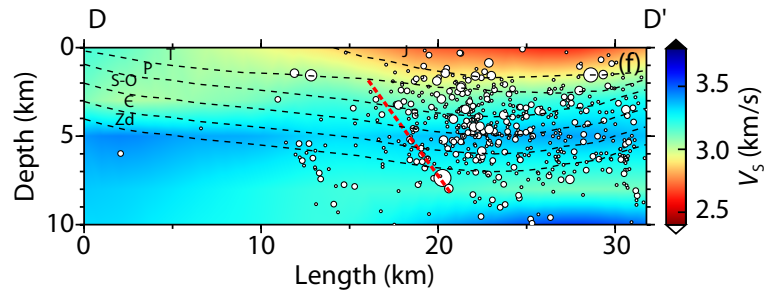

Figure 13. Vertical cross-sections of $P$ wave, $S$ wave velocity structure and focal depth at profiles $A A^{\prime}, B B^{\prime}$ and $D D^{\prime}$. The pink circles in $13 c$ and $d$ indicate the events observed by the seismic array.

hai-Tibet block. The focal mechanism solution showed that this earthquake was of strike-slip type; since one of the nodal planes is in the NW-SE direction, the NW-SE trending fault is very likely the seismogenic structure of this earthquake.

The Gongxian M5.3 earthquake occurred in the Jianwu syncline area, where it is conjectured that, in the epicentral area, besides the widespread NW-SE and NE-SW trending faults, small-scale near N-S faults may also exist; but the strike of these faults is not consistent with the near E-W Jianwu syncline. The focal mechanism solution indicates that this earthquake was caused by the rupture of a near N-S thrusting fault; therefore it should be caused by an accompanying blind thrust fault in the syncline area. In the geologic map (Figure 7c), the Gongxian M5.3 earthquake occurred at the boundary between the Jurassic and Triassic systems; the lithological difference between the two (Wang SZ, 2013) may induce compressional ruptures (red broken line in Figure 13e and f) under the southeasterly regional stress field (Xu ZH et al., 1987; Wang XS et al., 2015).

The Changning M6.0 earthquake occurred in the axial part of the Changning-Shuanghe anticline, and is of a strike-slip with thrusting type. Field investigations showed that the dominant direction of the meizoseismal area (Sichuan Earthquake Administration, 2019) is consistent with the long axis of the structural region, and also with the strike of one of the nodal planes of the focal mechanism solution of this earthquake. Therefore, the seismogenic structure of this earthquake should be one of the NW-SE trending strike-slip faults, and the earthquake sequence continues to the east segment of the Baixiangyan-Shizitan anticline. The Changning M6.0 and Xingwen M5.7 earthquakes have the same faulting type and direction, they belong to the same tectonic unit, i.e., the Changning-Shuanghe anticline structural region, while the
Gongxian M5.3 earthquake is controlled mainly by the Jianwu syncline; however, in terms of tectonic dynamics, all three are dominated by the interacting force between the Tibetan block and the South China block.

The occurrence of these three $M \geq 5$ earthquakes indicates that, under certain conditions, inside a tectonic block without largescale active structures, stress may nevertheless accumulate to a high degree and cause earthquakes. The profiles of the Changning and Xingwen earthquake sequences exhibit segmented distribution, indicating that in a structurally complex area the triggering effect of the mainshock stress is remarkable, and capable of further worsening the disaster caused by the mainshock. In summary, the Sichuan Basin and surrounding areas must be considered at significant risk of future strong earthquakes; this potential and its associated disaster prevention policy should therefore re-examined (Yi GX et al., 2019).

\section{Conclusion}

Benefiting from the combined use of data from the dense observation array and the regional station networks, we acquired the fine three dimensional earth structure and accurate source locations (May 2017 to September 2018) of the active earthquake swarm area of Changning-Gongxian in southeast Sichuan by using the tomoDD method, and then used hypoDD to locate the earthquake sequences of Xingwen M5.7, Gongxian M5.3, and Changning M6.0; by comprehensively analyzing various kinds of data, we reached the following conclusions:

(1) In regard to the velocity structures in the study region, the upper crust is generally laterally inhomogeneous. The locations of most high and low velocity anomalies accord with known geolo- 
gic structures; the degree of lateral inhomogeneity diminishes with increasing depth; that is, as depth increases the structure becomes more homogeneous the structure becomes; in some areas the structures in different depths are continuous to some degree, indicating that at particular positions the mediums in shallower and deeper parts interact with each other.

(2) In regard to the earthquake distribution, earthquakes are clustered in the study region, displaying a characteristic of multiple NW-SE and NE-SW belts alternatively folding; the dominant distribution direction of a single cluster is not obvious, but the long axis of the overall distribution of several adjacent clusters is generally consistent with the trend of nearby structures; the focal depths in the region are rather shallow, the great majority of earthquakes occurring in the sedimentary cover shallower than 6 km (Xiong XS et al., 2015; Wang WL et al., 2017), but some relatively large events took place in the crystalline basement, which is similar to the double seismogenic structure of sedimentary cover and crystalline basement in the neighboring Three Gorges reservoir area (Wu HB et al., 2018).

(3) In the velocity profiles, the scope of the near-surface top stratum can be well delineated, as well as the position of the top layer of the crystalline basement; the focal depth profiles exhibit the seismogenic structures of different size and attitude. Considered together with the velocity structure profiles at the same position, it can be seen that the areas of concentrated earthquakes are often related to P-wave high velocity regions; this is similar to the research result of Zhang Zhiwei et al. in the Zigong area (Zhang ZW et al., 2013); some S-wave high velocity zones are also regions of active earthquake swarms; fewer earthquakes occur in regions of low velocity S-waves.

(4) Combining the data of seismo-geology, field disaster investigation, and focal mechanism solutions, we suggest that the seismogenic structure of the Xingwen M5.7 and Changning M6.0 earthquakes is the associated NW-SE strike-slip fault in, respectively, the south wing and the axial part of the Changning-Shuanghe anticline, while the seismogenic structure of the Gongxian M5.3 earthquake is associated with the $\mathrm{N}-\mathrm{S}$ trending thrusting fault in the Jianwu syncline. The dynamic energy of these three earthquakes all came from southeastward compression of the Tibet-Qinghai against southern Sichuan. The relations between the spatial distribution of strong earthquakes and the velocity structure show that the Xingwen M5.7 earthquake of 2018 and the Gongxian M5.3 earthquake of 2019 are located in weak high anomaly zones of $P$ and $\mathrm{S}$ waves, while the Changning $M 6.0$ earthquake is in a region of high $\mathrm{P}$ velocity and high wave speed ratio.

(5) By examining data of the recent several years, we find that the southeast Sichuan area is possessed of the following characteristics: M5 strong earthquakes occur in succession, the stress in complex structure areas may easily be triggered, the small-scale fault segments may be locked, and the gaps may be filled. The risks of strong earthquakes in this area need to be re-examined.

\section{Acknowledgments}

We are grateful to Professor Zhang Haijiang of USTC for providing help in the method and software of tomoDD, Researchers Wen
Xueze, Jiang Changshen, Fang Lihua, and Li Yonghua for valuable suggestions, and two reviewers for their valuable comments; a part of the figures in the paper were plotted with GMT (Wessel and Smith, 1991). The research is supported by National Natural Science Foundation of China (No. 41574047), Sichuan-Yunnan national earthquake monitoring and prediction experimental field project (2016CESE0101, 2018CSES0209) and Project of Science for Earthquake Resilience (XH202302).

\section{References}

Chiarabba, C., and Amato, A. (2003). $V_{p}$ and $V_{p} / V_{s}$ images in the $M_{w} 6.0$ Colfiorito fault region (central Italy): a contribution to the understanding of seismotectonic and seismogenic processes. J. Geophys. Res. Solid Earth, 108(B5), 2248. https://doi.org/10.1029/2001JB001665

Cun, S. C., Shi, Y. J., and Chen, H. F. (1996). A synthesis study of drill and geophysical operations for the Shuanghe rock salt mining area. Journal of Chengdu Institute of Technology (in Chinese), 23(1), 100-104.

Gong, Y., Long, F., Qiao, H. Z., Zhao, M., and Wang, Y. X. (2015). Spatial and temporal distribution of seismic apparent stress in the southeast of Sichuan Province. Seismol. Geomagnet. Observ. Res. (in Chinese), 36(2), 6-12. https://doi.org/10.3969/j.issn.1003-3246.2015.02.002

Guo, Z. W. (1997). Natural gas exploration mode of shallow tight sand in the west part of Sichuan Basin. Natural gas industry (in Chinese), 17(3), 5-9.

Hofstetter, R., Dorbath, C., and Calò, M. (2012). Crustal structure of the Dead Sea Basin from local earthquake tomography. Geophys. J. Int., 189(1), 554-568. https://doi.org/10.1111/j.1365-246X.2012.05369.x

Huang, H. Y. (2018). Formation and evolution of paleo-uplift in southeastern Sichuan Basin and its control on hydrocarbon accumulation. A Dissertation Submitted to China University of Geosciences for Master Degree (in Chinese).

Kissling, E. (1988). Geotomography with local earthquake data. Rev. Geophys., 26(4), 659-698. https://doi.org/10.1029/RG026i004p00659

Kissling, E., Ellsworth, W. L., Eberhart-Phillips, D., and Kradolfer, U. (1994). Initial reference models in local earthquake tomography. J. Geophys. Res. Atmos. Solid Earth, 99(B10), 19635-19646. https://doi.org/10.1029/93JB03138

Kissling, E., Kradolfer, U., and Maurer, H. (1995). Program VELEST User's GuideShort Introduction. Institute of Geophysics, ETH Zurich.

Klein, F. W. (2002). User's Guide to HYPOINVERSE-2000, A Fortran Program to Solve for Earthquake Locations and Magnitudes. US: U.S. Geological Survey OpenFile Report, 02-171.

Lei, X. L., Huang, D. J., Su, J. R., Jiang, G. M., Wang, X. L., Wang, H., Guo, X., and Fu, $H$. (2017). Fault reactivation and earthquakes with magnitudes of up to $M_{\mathrm{w}} 4.7$ induced by shale-gas hydraulic fracturing in Sichuan Basin. China. Sci. Rep., 7(1), 7971. https://doi.org/10.1038/s41598-017-08557-y

Lei, X. L., Wang, Z. W., and Su, J. R. (2019). The December $2018 M_{\mathrm{L}} 5.7$ and January $2019 M_{\mathrm{L}} 5.3$ earthquakes in south Sichuan Basin induced by shale gas hydraulic fracturing. Seismol. Res. Lett., 90(3), 1099-1110. https://doi.org/10.1785/0220190182

Long, F., Du, F., Ruan, X., Deng, Y. Q., and Zhang, T. B. (2010). Water injection triggered earthquakes in the Zigong mineral wells in ETAS model. Earth. Res. China (in Chinese), 26(2), 164-171. https://doi.org/10.3969/j.issn.10014683.2010.02.004

Long, F., Wen, X. Z., Ruan, X., Zhao, M., and Yi, G. X. (2015). A more accurate relocation of the $2013 M_{s} 7.0$ Lushan, Sichuan, China, earthquake sequence, and the seismogenic structure analysis. J. Seismol., 19(3), 653-665. https://doi.org/10.1007/s10950-015-9485-0

Meng, L. Y., McGarr, A., Zhou, L. Q., and Zang, Y (2019). An Investigation of seismicity induced by hydraulic fracturing in the Sichuan Basin of China based on data from a temporary seismic network. Bull. Seismol. Soc. Am., 109(1), 348-357. https://doi.org/10.1785/0120180310

Mousavi, S., Bauer, K., Korn, M., and Hejrani, B. (2015). Seismic tomography reveals a mid-crustal intrusive body, fluid pathways and their relation to the earthquake swarms in West Bohemia/Vogtland. Geophys. J. Int., 203(2), 1113-1127. https://doi.org/10.1093/gji/ggv338

Nakajima, J., Matsuzawa, T., Hasegawa, A., and Zhao, D. P. (2001). Three- 
dimensional structure of $V_{p}, V_{s}$ and $V_{p} / V_{s}$ beneath northeastern Japan: implications for arc magmatism and fluids. J. Geophys. Res. Solid Earth, 106(B10), 21843-21857. https://doi.org/10.1029/2000JB000008

Okada, T., Yaginuma, T., Umino, N., Matsuzawa, T., Hasegawa, A., Zhang, H. J., and Thurber, C. H. (2006). Detailed imaging of the fault planes of the 2004 Niigata-Chuetsu, central Japan, earthquake sequence by double-difference tomography. Earth Planet. Sci. Lett., 244(1-2), 32-43. https://doi.org/10.1016/j.epsl.2006.02.010

Okada, T., Hasegawa, A., Suganomata, J., Umino, N., Zhang, H. J., and Thurber, C. $\mathrm{H}$. (2007). Imaging the heterogeneous source area of the 2003 M6.4 northern Miyagi earthquake, NE Japan, by double-difference tomography. Tectonophysics, 430(1-4), 67-81. https://doi.org/10.1016/j.tecto.2006.11.001

Parsons, T., Ji, C., and Kirby, E. (2008). Stress changes from the 2008 Wenchuan earthquake and increased hazard in the Sichuan basin. Nature, 454(7203), 509-510. https://doi.org/10.1038/nature07177

Qin, Z. P., Liu, S. G., Deng, B., Li, Z. W., and Sun, W. (2013). Multiphase structural features and evolution of southeast Sichuan tectonic belt in China. J. Chengdu Univ. Technol. (Sci. Technol. Ed.) (in Chinese), 40(6), 703-711. https://doi.org/10.3969/j.issn.1671-9727.2013.06.10

Ruan, X., Cheng, W. Z., Zhang, Y. J., Li, J., and Chen, Y. (2008). Research of the earthquakes induced by Water injections in Salt Mines in Changning, Sichuan. Earth. Res. China (in Chinese), 24(3), 226-234. https://doi.org/10.3969/j.issn.1001-4683.2008.03.004

Rybicki, K. (1973). Analysis of aftershocks on the basis of dislocation theory. Phys. Earth Planet. Inter., 7(4), 409-422. https://doi.org/10.1016/00319201(73)90020-4

Sichuan Earthquake Administration. (2019). Hazard Degree Map of the 17 June 2019 M6.0 Changning Earthquake. http://www.scdzj.gov.cn/dzpd/ybxwx53/ljdzyjxy/201906/t20190620_51774 .html.

Sichuan Geology Bureau. (1976). Regional Geological Survey Report. (Xuyong Geological Map Sheet, 1: 200000, in Chinese).

Sixth Division of the First Survey Team of Sichuan Geology Bureau. (1973). Regional geological survey report (Junlian geological map sheet, 1: 200000, in Chinese).

Sun, X. L., Yang, P. T., and Zhang, Z. W. (2017). A study of earthquakes induced by water injection in the Changning salt mine area, SW China. J. Asian Earth Sci., 136, 102-109. https://doi.org/10.1016/j.jseaes.2017.01.030

Thurber, C., and Eberhart-Phillips, D. (1999). Local earthquake tomography with flexible gridding. Comput. Geosci., 25(7), 809-818. https://doi.org/10.1016/S0098-3004(99)00007-2

Thurber, C. H. (1993). Local earthquake tomography: velocities and $V_{\mathrm{p}} / V_{\mathrm{S}}-$ theory. In H. M. Iyer, et al. (Eds.), Seismic Tomography: Theory and Practice (pp. 563-583). Boca Raton: Chapman and Hall.

Waldhauser, F., and Ellsworth, W. L. (2000). A double-difference earthquake location algorithm: method and application to the northern Hayward fault, California. Bull. Seismol. Soc. Am., 90(6), 1353-1368. https://doi.org/10.1785/0120000006

Wang, C. Z., Wu, J. P., Yang, T., Wang, W. L., Fan, L. P., and Fang, L. H. (2018). Crustal structure beneath the Taiyuan Basin and adjacent areas revealed by double-difference tomography. Chinese J. Geophys., 61(3), 963-974. https://doi.org/10.6038/cjg2018L0114

Wang, R., He, G. Q., Yin, Y. Q., and Cai, Y. E. (1980). A mathematical simulation for the pattern of seismic transference in north China. Acta Seismol. Sin. (in Chinese), 2(1), 32-42.

Wang, R., Sun, X. Y., and Cai, Y. E. (1983). A mathematical simulation of earthquake sequence in North China in the last 700 years. Sci. China (Ed. B),
XXVI(1), 103-112.

Wang, S. Z., Li, Z. Q., Guo, M., and Li H. K. (2013). Developmental characteristics of Longmaxi formation shaly fissure in Changning of south of Sichuan area. Sci. Technol. Eng. (in Chinese), 13(36), 10887-10898.

Wang, W. L., Wu, J. P., Fang, L. H., Lai, G. J., and Cai, Y. (2017). Crustal thickness and poisson's ratio in southwest China based on data from dense seismic arrays. J. Geophys. Res. Solid Earth, 122(9), 7219-7235. https://doi.org/10.1002/2017JB013978

Wang, X. S., Lü, J., Xie, Z. J., Long, F., Zhao, X. Y., and Zheng, Y. (2015). Focal mechanisms and tectonic stress field in the North-South Seismic Belt of China. Chinese J. Geophys. (in Chinese), 58(11), 4149-4162. https://doi.org/10.6038/cjg20151122

Wessel, P., and Smith, W. H. F. (1991). Free software helps map and display data. Eos. Transactions American Geophysical Union, 72(41), 441-446. https://doi.org/10.1029/90EO00319

Wu, H. B., Shen, X. L., Wang, J., Zhao, L. Y., and Chen, J. H. (2018). Threedimensional velocity structure of upper crust in the Three Gorges Reservoir area derived from double-difference tomography. Chinese J. Geophys. (in Chinese), 61(7), 2802-2814. https://doi.org/10.6038/cjg2018L0345

Wu, P., Su, J. R., Huang, C. M., Huang, D. J., and Duan, Y. G. (2017). Characteristic of shear-wave splitting in the Yibin area, Sichuan Province. Earth. Res. China (in Chinese), 33(3), 414-423. https://doi.org/10.3969/j.issn.10014683.2017.03.007

Xiao, Z., and Gao, Y. (2017). Crustal velocity structure beneath the northeastern Tibetan plateau and adjacent regions derived from double difference tomography. Chinese J. Geophys. (in Chinese), 60(6), 2213-2225. https://doi.org/10.6038/cjg20170615

Xiong, X. S., Gao, R., Zhang, J. S., Wang, H. Y., and Guo, L. H. (2015). Differences of structure in mid-lower crust between the eastern and western blocks of the Sichuan basin. Chinese J. Geophys. (in Chinese), 58(7), 2413-2423. https://doi.org/10.6038/cjg20150718

Xu, Z. H., Wang, S. Y., Huang, Y. R., Gao, A. J., Jin, X. F., and Chang, X. D. (1987). Directions of mean stress axes in southwestern China deduced from microearthquake data. Chinese J. Geophys. (in Chinese), 30(5), 476-486.

Yi, G. X, Long, F., Liang, M. J., Zhao, M., Wang, S. W., Gong, Y., Qiao, H. Z., and Su, J. R. (2019). Focal mechanism solutions and seismogenic structure of the 17 June 2019 MS6.0 Sichuan Changning earthquake sequence. Chinese J. Geophys. (in Chinese), 62(9), 3432-3447. https://doi.org/10.6038/cjg2019N0297

Zhang, H. J., and Thurber, C. H. (2003). Double-difference tomography: the method and its application to the Hayward fault, California. Bull. Seismol. Soc. Am., 93(5), 1875-1889. https://doi.org/10.1785/0120020190

Zhang, H. J., and Thurber, C. (2006). Development and applications of doubledifference seismic tomography. Pure Appl. Geophys., 163(2-3), 373-403. https://doi.org/10.1007/s00024-005-0021-y

Zhang, Z. W., Cheng, W. Z., Wu, P., Gong, Y., Chen, W. K., Xu, Y., and Zhou, X. Z. (2013). Study on earthquake relocation and $P$-wave velocity structure in the Zigong and Longchang area. Earth. Res. China (in Chinese), 29(1), 37-47. https://doi.org/10.3969/j.issn.1001-4683.2013.01.004

Zhao, Z., and Zhang, R. S. (1987). Primary study of crustal and upper mantle velocity structure of Sichuan province. Acta Seismol. Sin.(in Chinese), 9(2), 154-166.

Zhu, H., and He, C. (2014). Focal Mechanism Changning character of earthquake sequence induced by water injection: a case study of Changning sequence, Sichuan Province. Earth Sci. J. China Univ. Geosci. (in Chinese), 39(12), 1776-1782. 